NOTICE

PORTIONS OF THIS REPORT ARE ILLEGIBLE. It has been reproduced from the best available copy to permit the broadest possible availability.

Prepared by

Republic Geothermal, Inc.

11823 East Slauson Ave.

Santa Fe Springs, California 90670

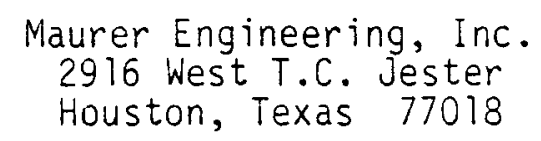

and

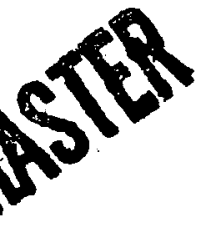

Vetter Research

3189-C Airway Avenue

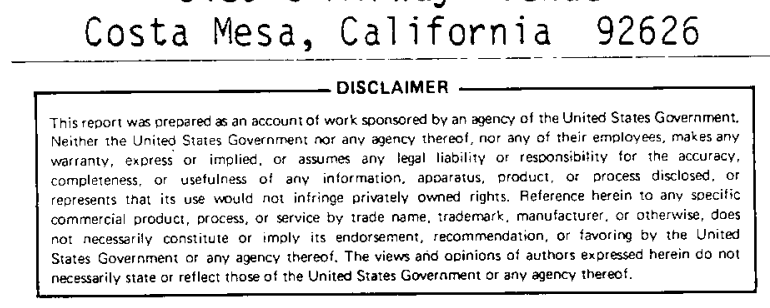

for

The Department of Energy

Under Contract No. DE-ACO4-79AL 10563 


\section{DISCLAIMER}

This report was prepared as an account of work sponsored by an agency of the United States Government. Neither the United States Government nor any agency Thereof, nor any of their employees, makes any warranty, express or implied, or assumes any legal liability or responsibility for the accuracy, completeness, or usefulness of any information, apparatus, product, or process disclosed, or represents that its use would not infringe privately owned rights. Reference herein to any specific commercial product, process, or service by trade name, trademark, manufacturer, or otherwise does not necessarily constitute or imply its endorsement, recommendation, or favoring by the United States Government or any agency thereof. The views and opinions of authors expressed herein do not necessarily state or reflect those of the United States Government or any agency thereof. 


\section{DISCLAIMER}

Portions of this document may be illegible in electronic image products. Images are produced from the best available original document. 


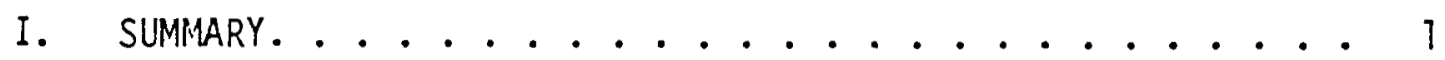

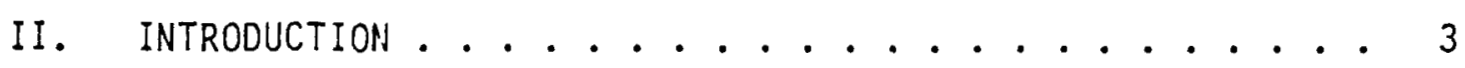

III. RESERVOIR REVIEW ................. 5

A. Geology................. 5

B. Well Selection. ............ 6

IV. PRE-STIMULATION STUDY OF WELL. ............ . 7

V. EXPERIMENT NO. 3 - PLANAR FRACTURE STIMULATION . . . . 9

A. Pre-stimulation Evaluation. ......... 9

B. Subsurface Well Work. .......... 10

C. Stimulation Treatment........... 11

D. Introduction of Tracers .......... 12

E. Theoretical Fracture Length Computation . . . . 13

VI. EXPERIMENT NO. 4 - DENDRITIC FRACTURE STIMULATION. . . . 14

A. Pre-stimulation Evaluation. ......... 14

B. Subsurface Well Work. ........... 15

C. Stimulation Treatment .......... 16

D. Introduction of Tracers ......... 18

E. Theoretical Fracture Length Computation . . . . . 19

VII. POST-STIMULATION WELL TESTS. . . . . . . . 20

A. Post-Stimulation Evaluation - Experiment No. 4. . . 20

B. Post-Stimulation Evaluation - Experiment No. 3. . . 24

VIII. EXPERIMENT COSTS ................... 28

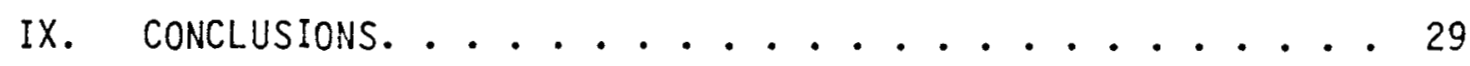

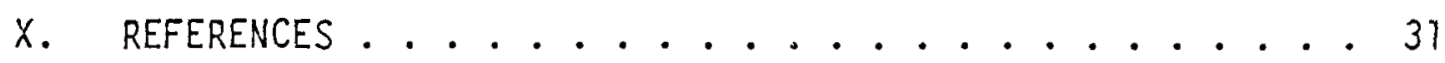

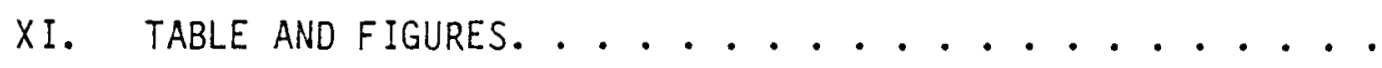

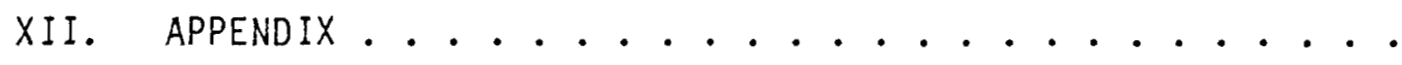


1 East Mesa 58-30 Production Log Results

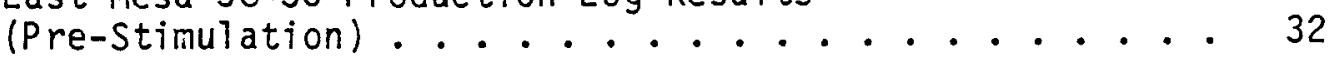

2 East Mesa 58-30 Pre-Stimulation Pressure Buildup

Test for Entire Wellbore............. 33

3 East Mesa 58-30 Conventional (Planar) Fracture

Treatment ................. . . 34

4 East Mesa 58-30 (Deep Zone) Conventional (Planar)

Fracture Treatment Summary--7/3/80. . . . . . . . 35

5 Analysis of Fluids Used for Experiment No. 3. . . . . 36

6 East Mesa 58-30 Experiment No. 3 (Lower Zone) Planar

Fracture Length .............. . 37

7 Typical Stage of Dendritic Treatment. . . . . . . . . 38

8 East Mesa 58-30 (Shallow Zone) 5-Stage Dendritic Fracture Treatment Sumary--7/6/80........... 39

9 Analysis of Frac Fluid Samples from Blender before Injection, Experiment No. 4-July 6, 1980. . . . . . 40

10 Analysis of Flowback Samples after Experiment No.4 - July 6,1980........... 41

11 East Mesa 58-30 Experiment No. 4 (Upper Zone) Dendritic Fracture Lengths. . . . . . . . . . . 42

12 Temperature - Distance Relationship in Fractures. . . . 43

13 Chemical Analyses for Well. 58-30 Flow Test 7/25-8/2/80. . 44

14 Downhole Samples Taken July 29, 1980......... . 48

15 East Mesa 58-30 Pressure Buildup Data, Upper and Intermediate Zones Open...............

16 East Mesa 58-30 Production Log Results (PostStimulation).................... 50

17 Chemical Analyses for Well 58-30 Flow Test 12/15-23/80. • 51 


\section{LIST OF TABLES (continued)}

Table

Page

18 East Mesa 58-30 Pressure Buildup Data for Entire Well bore $(12 / 23-29 / 80)$............. . 55

19 East Mesa 58-30, Summary of Production Test Data . . . . 56

20 Field Costs for Experiments Nos. 3 and 4 . . . . . . 57 


\section{LIST OF FIGURES}

Figure

Page

1 Location of East Mesa 58-30............ 58

2 Completion Detail - East Mesa 58-30 . . . . . . . 59

3 East Mesa 58-30 Flow Test, Prior to Stimulation . . . . 60

4 East Mesa 58-30 Pre-Stimulation Production Log Detai1s. . . 61

5 East Mesa 58-30 Horner Buildup Data (6/24-26/80). . . . . 62

6 East Mesa 58-30 Zonal Isolation for Frac Treatments . . . 63

7 Pressure-Rate History, East Mesa 58-30 Experiment No. 3 . . 64

8 Flow Schematic for Experiments at East Mesa 58-30 . . . 65

9 Pressure-Rate History, East Mesa 58-30 Experiment

No. 4 ................... 66

10 East Mesa 58-30 Static Temperature Survey of Upper and Intermediate Intervals after Experiment No. $4 . . .667$

11 East Mesa 58-30 Flow Test, Upper and Intermediate Zones . 68

12 Tracer Monitoring for Flow Test - (7/25-8/2/80)

(Upper Interval--Experiment No. 4). . . . . . . . . 69

13 Tritium Monitoring for Flow Test - (7/25-8/2/80)

(Upper Interval--Experiment No.4). . . . . . . . 70

14 East Mesa 58-30 LBL Flowing Temperature Survey. . . . . . 71

15 East Mesa 58-30 Horner Buildup Data (8/2-5/80) . . . . 72

16 East Mesa 58-30 Flow Test, Post-Stimulation, Full

Wellbore Open (12/15-30/80) . . . . . . . . . 73

17 East Mesa 58-30 Post-Stimulation Production Log

Details................. . . 74

18 Tracer Monitoring for Second Flow Test - (12/15-23/80). • 75

19 Tritium Tracer Monitoring for Second Flow Test

$(12 / 15-23 / 80)$. . . . . . . . . . . . . . . 76

20 East Mesa 58-30 Horner Buildup Data (12/23-29/80) . . . 77 


\section{SUMMARY}

Republic Geothermal, Inc. and its subcontractors, as part of the Geothermal Reservoir Well Stimulation Program funded by the U.S. Department of Energy/Oivision of Geothermal Energy, performed two field experiments at the East Mesa KGRA in 1980. East Mesa Well 58-30 was selected for two stimulation treatments: a conventional hydraulic fracture in a deep, low permeability interval, and a dendritic fracture in a shallow, high permeability interval of completion. The well selection, pre-stimulation evaluation, fracture treatment design, and post-stimulation evaluation are presented herein.

The program goal is to develop stimulation techniques for geothermal producing wells. Republic is the program manager, and the active subcontractors are Maurer Engineering Inc. and Vetter Research. The three-year program includes a review of the existing technology, laboratory studies, and eight field experiments. The East Mesa stimulation treatments (Experiments Nos. 3 and 4 in this series) represent the first experiments of this program in a matrix porosity system. The selection of East ilesa 58-30 represents a step-up in temperature over previous experiments in the Raft River field. ${ }^{4}$ The East Mesa KGRA is located with in a moderate temperature $\left(320-400^{\circ} \mathrm{F}\right.$ ) reservoir producing from a river-deltaic, sandstone-siltstone complex. This reservoir has been studied extensively by Republic and others and has a large quantity of information available. 
East Mesa 58-30 provided an unusual opportunity to perform both of these experiments in the same well due to the mechanical condition of the wellbore and the reservoir parameters. Mechanically, the well was one of the few geothermal wells completed with a cemented, jetperforated liner. This completion method permitted the use of simplified techniques for zonal isolation of the treated interval. The upper and lower interval sands were used to test different hydraulic stimulation techniques within one well.

Experiment No. 3 consisted of a conventional planar-type fracture stimulation of a lower interval (6834'-6587') which had good sand development, but where the permeability had been severely reduced because of authigenic cementation by carbonates and quartz. The porosity was still high enough to provide good storage capacity, however. The objective of this treatment was to create more effective wellbore drainage and thereby enhance the well's flow capacity. The treatment consisted of 2,800 bbl of a viscous crosslinked polymer frac fluid and 120,000 1b of proppant sand. The fluid was pumped at an average rate of 40 BPM. The treatment yielded an increase of 19 percent in interval permeability-thickness $(k h)$ and 84 percent in fluid production. The increased volume of hotter fluid from this lower interval lowered the wellbore flash point, decreased the downhole flowing pressure, and thus improved the overall well production rate disproportionate to the $\mathrm{kh}$ increase. 
Experiment No. 4 was designed to create a series of shallow fractures or mini-fracs in an upper interval (5256'-4952') which consisted of high permeability sands with a high matrix porosity. This upper interval, drilled with a predominantly bentonitic mud system, had good sands which demonstrated permeability impairment near the wellbore. The treatment was designed to break through the damaged zone so that fluid could more easily flow into the wellbore from the formation. The treatment consisted of 10,300 bbl of low viscosity frac fluid and 44,000 lb of 100-mesh sand (as a fluid-loss additive) pumped in five stages at an average rate of 48 BPM. No proppant was utilized in this treatment. The treatment improved the permeability-thickness of the upper interval by 108 percent and the fluid production by 137 percent.

In summary, Wel1 58-30 was successfully stimulated by the two fracture treatments. Although some of the initial improvement was lost during workover operations, at the completion of the experiment the overall productivity of the well had been increased 114 percent and the $\mathrm{kh}$ had been increased 38 percent. The techniques and materials utilized at East Mesa appear to be capable of withstanding the moderate temperature geothermal environment.

\section{INTRODUCTION}

The Geothermal Reservoir Well Stimulation Program (GRWSP) was initiated to develop the technology required for the stimulation of eothermal wells. The project was divided into two phases: Phase I 
consisted of studies (1iterature and theoretical), laboratory

investigations, and numerical work; Phase II involved full-scale field experiments to evaluate geothermal well stimulation technology.

The GRWSP performed two field experiments in one well at the East Mesa KGRA in the Imperial Valley of California during July 1980. The East Mesa KGRA is a moderate temperature reservoir producing geothermal waters containing less than $2,000 \mathrm{mg} / 1$ in total dissolved solids (TDS) from a sandstone and siltstone rock matrix. This reservoir has been extensively studied by Republic Geothermal, Inc. (RGI) and others, and therefore, there is a large quantity of information available on the reservoir. The reservoir temperature range $\left(320-400^{\circ} \mathrm{F}\right)$ made this project the next logical step for Phase II field experiments under the GRWSP and was in keeping with recommended sequence in the "Reservoir Selection Task" report of November 1979.'

The field experiments consisted of two hydraulic fracture stimulation treatments in East Mesa 58-30. The first of the two experiments was a conventional type (planar) fracture stimulation. The second was designed to create a series of shallow fractures to penetrate near-wellbore mud and cement damage in a shallower, high permeability interval. Both situations are common in geothermal wells and the results will have a broad application to the geothermal industry. This report documents these stimulation experiments. 


\section{RESERVOIR REVIEW}

A. Geology

The East Mesa KGRA is located in an area of anomalously high heat flow on the east flank of the Salton Trough, at the southeast corner of the Imperial Valley of California. Twenty-three deep wells have been drilled within the KGRA, including ten by RGI in the northern portion, five by the U.S. Bureau of Reclamation in the central area, and eight by Magma Power Co. to the south (Figure 1).

The existing well control and seismic data at East Mesa indicate that the field is located on a closed anticline that trends $\mathrm{N}^{2} \mathrm{O}-30 \mathrm{~W}$. This structure is actually somewhat asymmetric as the western (basin-ward) flank dips more steeply than the eastern limb. A large structural high is present immediately to the east. Logs, ditch cuttings, and cores show that the upper 10,000 feet of stratigraphic section at East Mesa is a sequence of deltaic clastic sediments that include abundant amounts of fine-to-medium-grained sandstones, fine-tocoarse-grained siltstones, and lesser amounts of mudstones. Mineralogically, the sands are compositionally equivalent to Colorado River delta sands, being mostly quartz (70 percent), lithic fragments (20 percent), and feidspars (10 percent). The separate sands, silts, and mudstones occur as a vertically alternating sequence in which the individual sandbeds normally range between 10 and 60 feet in thickness with thinner intervening shales. Post-depositional alterations are 
principally the addition of authigenic carbonate and quartz as overgrowths and veinlets, and the conversion of the detrital clays to illite and chlorite.

\section{B. Well Selection}

The selection criteria of East Mesa 58-30 for the stimulation included both the reservoir (production) and mechanical condition of the we11. Of the 16 producing wells at East Mesa, 58-30 was considered an especially good prospect for stimulation. The primary reasons were:

(1) the well is completed with a cemented, jet-perforated liner

(Figure 2); (2) 58-30 is a noncommercial producer but adjacent to 38-30, an excellent producer; (3) all reservoir calculations indicate that 58-30 is located in a limited, low permeability zone which could be the cause of the reduced productive capacity; and (4) the location of 58-30 was about 1,300 feet from three wells (38-30, 78-30 RD, and 56-30) which could be utilized as pressure observation wells (Figure 1). No expensive workover operations on 58-30 were required prior to the experiments.

We11 58-30 was the first well completed at East Mesa with a cemented liner. Most of the other wells have slotted liner completions. The well was first perforated in the intermediate $\left(5483^{\prime}-6564^{\prime}\right)$ and lower $\left(6587^{\prime}-6834^{\prime}\right)$ sands. The perforated sands had low permeabilities and productivity. To improve well productivity, the upper interval $\left(4952^{\prime}-5256^{\prime}\right)$ was perforated. Although the upper interval consisted of high permeability sands, fluid production was low. The upper interval 
was reperforated and washed with geothermal fluids; however, little improvement in productivity occurred. Results of the reperforation and washing indicated that deep formation damage was present which could be attributed to drilling mud and/or cement filtrate invasion. The existence of the lower and upper interval in one well with a cemented, jet-perforated liner for vertical segregation made the well an ideal choice for the proposed stimulation techniques.

The near-wellbore type of formation damage in this well has been historically handied by acid stimulation or by "mini-fracs" in oil and gas wells. Conventional acid treatments have been tried at East Mesa with generally poor results. Therefore, hydraulic fracturing was considered to have the best chance of successfully fracturing the selected intervals.

\section{PRE-STIMULATION STUDY OF WELL}

The zones selected for Experiments Nos. 3 and 4 consisted of layered, well consolidated sandstone. An interval in the deeper portion of the well (6834'-6587') was selected for Experiment No. 3, and an interval in the upper portion of the well (5256'-4952') was selected for Experiment No. 4 (Figure 2). The testing and treating operations are summarized in the following sections. The daily operational reports of these experiments are given in Appendix $A$. 
To monitor well flow, a 12 -inch 1 ine was installed from the wellhead to a separator. The produced fluid from 58-30 was then flashed through the separator and orifice meters used to measure the steam and liquid flow rates. In addition, the flow line pressure and temperature were continuously monitored. The steam flow was vented to atmosphere and the liquid portion injected by pumping it down an injection well. Fluid and steam samples were collected from the steam and fluid lines downstream of the separator.

Individual isolation of the two intervals designated for stimulation was not easily obtainable for production testing. Therefore, it was decided to record the inflow characteristics of the entire well and prorate fluid production by means of a spinner survey. Starting June 17, the we11 was "kicked-off" and permitted to flow for 163 hours at an average rate of $92,300 \mathrm{lb} / \mathrm{hr}$ (Figure 3 ). A spinner and continuous temperature $\log$ was run from 6,820 feet to 4,500 feet (Figure 4) to determine inflow zones. The spinner readings were utilized for proportioning the fluid inflow to the lower, intermediate, and upper intervals as shown in Figure 4 and Table 1.

The well was then shut in and the bottomhole pressure buildup was recorded (Table 2). A conventional Horner buildup computation from this data is shown in Figure 5 . The computed permeability-thickness (kh) was 7,493 md-ft for the entire wellbore. 


\section{EXPERIMENT NO. 3 - PLANAR FRACTURE STIMULATION}

A. Pre-stimulation Evaluation

The zone selected for Experiment No. 3 consisted of a layered, well consolidated sandstone. The deep zone from 6,834 feet to 6,587 feet (a 247-foot interval) had a net sand thickness of 199 feet with an average $\log$ calculated air permeability of $55 \mathrm{md}$. Sections of nonperforated casing of 23 feet and 51 feet respectively above and below the treated interval, with good cement bonaing through this interval as indicated by cement bond logs, offered an excellent opportunity of maintaining zonal isolation during treatment.

The treated interval had good sand development but low permeability, probably due to authigenic cementation by carbonates and quartz. The fluid permeabilities in this interval (15-20 md) are in the high range of those normaliy encountered in $0 i 1$ and gas wells. The treatment utilized was a conventional hydraulic fracture using a high viscosity frac fluid carrying a high sand concentration to create a wide propped fracture.

The interval treated was not independently tested prior to stimulation. Rather, the productivity of the entire wellbore was measured and then allocated on the basis of the spinner survey (Table 1). The production from the lower interval represented 29 percent of 
the total flow; and based upon linear allocation, 2,173 md-ft for the pre-stimulation $\mathrm{kh}$. The average flowing temperature at the top of the lower interval $\left(6,587^{\prime}\right)$ was $347^{\circ} \mathrm{F}$.

8. Subsurface Well Work

In preparation for isolating and treating the lower interval, a casing scraper was run to a depth of 6,715 feet in the $7-5 / 8$ inch 1 iner to eliminate burrs or scale which might interfere with a packoff above the treatment interval. A mechanical collar locator was also run on tubing to locate a reference casing collar above the treatment interval and thereby calibrate tubing measurements to perforation depths which are known with respect to casing collars. A pair of Lynes inflatable packers were used to keep the fracture fluid contained (Figure 6A). Two inflatable packers were utilized rather than a single conventional packer as the 23-foot blank interval (6564'-6587') was not considered sufficient for reliable containment of the treatment. Each packer had a $5-1 / 2$ foot long element. The lower packer was set near the top of the 23-foot blank. The upper packer was set with the elements spanning the interval 6,423 feet to 6,429 feet. Thus, a 64-foot interval $\left(6423^{\prime}-6587^{\prime}\right)$, which includes several shale layers, was effectively packed off above the treatment interval. This reduced the risk of losing confinement of the treatment due to vertical fracture growth or a breakdown of the liner cement. The treatment was successfully confined below the packers. 


\section{Stimulation Treatment}

The fracturing work for both experiments was awarded to BJ-Hughes, Inc. on the basis of competitive bid. Several operational difficulties occurred during the fracturing process; however, none was serious enough to prevent successful completion of the treatment. First, the flow meter broke after 1,330 bbl had been pumped into the treated interval. The frac tank fluid levels were monitored after that point to maintain an average flow rate of 40 BPM. Slight variations in the flow rate are believed to have occurred during the last half of the treatment, but measurement was not possible. The importance of monitoring flow rate is that it can be utilized in understanding surface pressure fluctuations, and indirectly, fracture growth.

A second problem resulted in approximately 10 percent less proppant being injected than was called for in the design. This problem may be related to the use of a resin-coated sand, a faulty sand gate, or operator error. The materials and sequence in which they were injected are shown in Table 3 .

The water in the pit had a temperature of about $90^{\circ} \mathrm{F}$ and caused minor problems in gelling the hydroxypropyl guar (HP guar) as polymer "fish eyes" formed and floated to the top of the tanks. The polymer mix, however, gelled sufficiently to increase the water viscosity to the desired level. 
Figure 7 illustrates the surface pressure and flow rate measured during the job. Although precise measurement was not possible, the flow rate remained relatively constant at $40 \mathrm{BPM}$. Instantaneous shut-in pressure measured about 600 psig at the beginning of the treatment and about 2,000 psig after the treatment. The calculated frac gradients from these values were $0.52 \mathrm{psi} / \mathrm{ft}$ and $0.73 \mathrm{psi} / \mathrm{ft}$ respectively. The last part of the pressure curve in Figure 7 indicates a buildup of pressure, probably due to narrowing and/or sanding out of the fracture.

The maximum horsepower available from the six pump trucks on site was calculated to be 4,400 hhp, or two-thirds of their rating. The high ambient air temperatures of $100-115^{\circ} \mathrm{F}$ contributed to overheating of the pump transmissions, and therefore, pump output had to be curtailed to avert a breakdown. The surface positioning of equipment is shown in Figure 8 .

Table 4 summarizes the quantities of sand and crosslinked polymer gel utilized for the experiment. A total of $163,7001 \mathrm{~b}$ of sand and resin-coated sand, and 2,800 bbl of fluid were injected downhole.

\section{Introduction of Tracers}

The fracture fluid described in Section $C$ was mixed prior to the start of the fracturing operation. Samples of the gelled fluid were taken before and at 20-minute intervals during pumping. These samples were analyzed for carbohydrate (CHO), total organic carbon (TOC), and 
ammonium. The analytical results are presented in Table 5. These tests showed an average polymer concentration in the frac fluid of about 7,404 $\operatorname{ppm}(61.7$ 1b/1000 ga1).

Both chemical and radioactive tracers were added to the fracture fluids. The chemical tracer was ammonium nitrate $\left(\mathrm{NH}_{4} \mathrm{NO}_{3}\right)$. The radioactive tracers were iodide 131 (as $\mathrm{NaI}$ ) and sulfur 35 [as sodium sulfate $\mathrm{Na}_{2}\left(\mathrm{SO}_{4}\right)$ ]. Nonradioactive $\mathrm{NaI}$ was added with the radioactive material in order to reduce adsorption of the iodide on the formation. Only the first 200 barrels of the frac fluid were treated with the radioactive tracers as a result of problems with the tracer injection pump. This represented injection of 15 percent of the total radioactive tracer as originally called for in the program.

Four hundred and fifty pounds of ammonium nitrate were added to the gelled fracture fluid in the mixing tanks. This represented a concentration of 103 ppm for $\mathrm{NH}_{4}$. Also 25 pounds of sodium iodide were added to the fluid through the blender while the fluid was pumped into the wel1. The iodide concentration was about $21.5 \mathrm{ppm}$.

\section{E. Theoretical Fracture Length Computation}

The treatment was originally designed to create a 400-foot long fracture, assuming a 50 BPM pumping rate. The actual 40 BPM pumping rate can be presumed to have resulted in a shorter fracture. Table 6 presents fracture design computations indicating the length of the fracture, fracture width versus time, and cumulative volume of injected 
fluid for the lower pumping rate. ${ }^{5}$ The maximum length of the fracture was computed to be 184 feet. If fully propped so that the fracture does not close, then the width and length of fracture should be similar to those volumes shown in the table. McGuire and sikora ${ }^{3}$ have presented data on a well's stimulation ratio as a function of relative conductivity and length of the fracture. Using the calculated values, the fracture's conductivity (width times permeability) is 0.2 inches $x$ $10^{5} \mathrm{md}$, or about $20,000 \mathrm{md}-\mathrm{in}$. In a $20 \mathrm{md}$ formation, this yields a relative fracture conductivity of $10^{3} \mathrm{md}-\mathrm{in} / \mathrm{md}$. Assuming the ratio of frac length to well drainage radius is 0.277 , the stimulation ratio in an undamaged formation would be a factor of 2.0. A longer fracture of the same relative conductivity does not yield a higher stimulation ratio.

\section{EXPERIMENT NO. 4 - DENDRITIC FRACTURE STIMULATION}

\section{A. Pre-stimulation Evaluation}

This experiment consisted of a shallow mini-frac stimulation of a high permeability, less consolidated upper interval (5256'-4952'). This interval of 304 feet had a net sand height of 219 feet with an average air permeability of 150 md calculated from the electric log data. The production tests indicated a geothermal fluid permeability-thickness of $2,848 \mathrm{md}-\mathrm{ft}$, one-third to one-half of what might normally be anticipated from similar zones in the East Mesa field. 
Because this interval had not originally been intended as a

producing interval, it was drilled with a bentonitic clay mud, and casing was cemented in place with no attempt to clean up the wellbore surface. Therefore, clay solids and cement filtrate invasion both contributed to the near-wellbore formation damage. Problems of this type are often handled by mini-fracs or acidization in the $0 i 1$ industry. Conventional acid treatments have been attempted in the East Mesa field with little success in well stimulation.

\section{B. Subsurface Well Work}

The schematic of subsurface equipment for this experiment is shown in Figure 68. The upper treatment interval (5256'-4952') of 304 feet was to be isolated between a bridge plug and packer. A Baker model "EA" Retrievamatic Packer was run in the hole on the 4-1/2 inch tubing frac string with a model " $C$ " bridge plug attached below in tandem. When the bridge plug is run in this manner, a tandem running tool made up on the bottom of the packer provides for release and setting of the bridge plug at the desired depth. The intent was to release the bridge plug at 5,270 feet, then pull the packer up to about 4,500 feet, and set it as shown in Figure 6B. While running the packer and bridge plug in tandem, a depth measurement error was made, and the 10-3/4 inch bridge plug was rammed into the $10-3 / 4 " \times 7-5 / 8 " 1$ iner hanger at 5,276 feet. (When retrieved after the stimulation process, it was found that the bottom portion of the bridge plug had fallen off and lodged on top of the liner hanger.) The unit was then pulled up to 5,270 feet, and the setting procedure for the bridge plug was performed. The action to detach the 
bridge plug from the packer was performed and the packer was pulled up to 4,458 feet. Although it was not known at that time, the impact of jamming the bridge plug on top of the liner hanger had caused the bridge plug to jam in the running tool, and thus it did not detach from below the packer. When pumping first began, the upper cup on the bridge plug was ruptured allowing the job to proceed in an apparently normal manner. However, with the bridge plug still attached, the flow was restricted at that point. This contributed to later problems in which lower than designed pumping rates were achieved.

Ten cubic feet of sand were pumped down the tubing with the intent that it would settle out above the bridge plug set at 5,270 feet. A portion of this sand did settle out on the bridge plug components that had broken off and lodged on the liner hanger. This sand plug seal did not appear to completely segregate the upper interval from the intermediate interval for the stimulation treatment.

c. Stimulation Treatment

The plan for this experiment was a $14,800 \mathrm{bbl}$ dendritic fracturing treatment to be pumped in eight stages of $1,850 \mathrm{bb} 1$ each. The frac fluid was a low viscosity polymer gel designed to contain ten pounds of hydroxypropyl guar and two pounds XC polymer per 1000/gal of water. These polymers were added to the fluid as it was pumped. Subsequent chemical analysis of the injected fluid indicated a somewhat higher polymer concentration -- probably resulting from polymer retention in the frac tanks from the previous job. One-hundred mesh Nevada sand and 
20 lb of finely ground calcium carbonate per 1000/gal were added as fluid-loss additives. The injection of 100-mesh sand was also intended to erode flow channels in the fracture faces. No proppant material was used in the dendritic frac treatment. A 10,000 bol pit at the 58-30 well location was enlarged and lined with clay and rock to provide a large fluid storage basin for the frac fluid. Figure 8 is a flow schematic of the fracturing equipment. The four 500-bbl frac tanks shown in the figure provided about 30 minutes of residence time needed for hydration of the polymer before the sand was added.

The pressure-rate history of the treatment is presented in Figure 9. Only five stages, rather than the proposed eight stages, were injected as the pit could not be refilled as fast as anticipated, and there was insufficient fluid in the pit for another stage. The first four stages proceeded as planned; however, $444 \mathrm{bb}$ into the fifth stage, the pump trucks ran out of fuel and pumping was suspended until they could be refueled. A typical stage is shown in Table 7. Table 8 shows the total volume of fluids and solids for the stimulation treatment. Each of the first four stages was approximately 40 minutes in length. In the fifth stage, the pad preceding the first sand slug was increased from $700 \mathrm{bbl}$ to $1,000 \mathrm{bbl}$. The total fluid volume for the fifth stage was 2,156 bb1. During treatment, the instantaneous shut-in pressures varied from 1,100 to 1,360 psig, giving frac gradient readings of 0.65 to $0.70 \mathrm{psi} / \mathrm{ft}$. 
Again, the highest pump truck horsepower generated was much less than the rated horsepower of the trucks. The desired pumping rate of 50 BPM could not be achieved because the frac units were undersized for the hot weather.

\section{Introduction of Tracers}

As discussed in Section C, a total of 10,300 barrels of fracture fluid was utilized for the upper zone treatment, and Table 9 shows the chemical analysis of the fracture fluid from each stage. The weighted average polymer concentration was 3,265 ppm, or about 0.3 percent by weight.

Tritium $\left({ }^{3} H\right)$ was utilized as the primary tracer for the upper interval. The tritium was added directly into the fracture fluid stream at the pump truck suction for a total of 4 curies of tritium. The total concentration was 6,085 disintegrations per minute per $\mathrm{ml}(\mathrm{dpm} / \mathrm{ml})$. Table 10 shows the tracer concentration in the produced fluid from the upper interval which was immediately flowed back for 60 minutes after the last stage of the fracture treatment. The analyses also indicated no tracer was present which had been placed in the frac fluid for the lower treated interval (i.e., radioactive iodide, sulfate, or ammonium). This indicates that there was no communication with the previously treated lower zone frac fluid. The analysis shows an average of 2,593 ppm for the $\mathrm{CHO}$ and 1,096 ppm for the TOC. Based upon the 
concentration of $\mathrm{CHO}$ and TOC from Table 9 , this analys is indicates an immediate dilution of the frac fluid by formation waters of about 20 percent.

\section{E. Theoretical Fracture Length Computation}

The dendritic fracture treatment consisted of five stages, the first four of which were 40 minutes in length. At the close of each stage, the well was back flowed and the fracture had the opportunity to close and terminate its growth. Fracture calculations for the East Mesa formation material (Table 11) indicate that for a time period of 40 minutes, one could expect a 93-foot fracture length. 5 The fracture was designed to be held open by formation material spalling off the sides of the fracture. Erosion on the fracture faces by the frac fluid and 100-mesh sand is also believed to create flow channels. The maximum production increase estimated by the MicGuire and Sikora ${ }^{3}$ plot indicates a stimulation ratio of two, assuming a $10^{6} \mathrm{md}$ fracture permeability, a 0.054 inch fracture width, and a formation permeability to water of $55 \mathrm{md}$. The calculated theoretical temperature of the frac fluid in the fracture, assuming an extremely high leak-off rate, is given in Table 12. After 40 minutes of pumping, near the end of the stage, the table shows that much of the fluid in the fracture was at less than $300^{\circ} \mathrm{F}$ and, therefore, should not have suffered excessive thermal degradation. 


\section{POST-STIMULATION WELL TESTS}

A. Post-Stimulation Evaluation - Experiment No. 4

Following the completion of Experiment No. 4, the packer was pulled from the well and it was discovered that the bridge plug had remained underneath the packer during the stimulation treatment. A sand bailer was run, and approximately three feet of sand fill was found above the liner hanger at 5,276 feet. The sand had bridged on the debris which had broken off the bridge plug when it had been jammed into the 7 iner hanger. Analysis of the sand fill showed that the lower portion consisted of the sand originally dropped to cap the bridge plug. The upper portion was a mixture of the sand utilized for capping the bridge plug and that used in the fracturing operations. The junk was then removed from the liner top, and the well was found to be open to a depth of 6,551 feet. Sand fi11 at that depth covered the Experiment No. 3 treatment interval. A continuous temperature survey was then run (Figure 10).

Nitrogen was utilized to lift the kill fluid from the wellbore and initiate well flow. The well was flowed for 186 hours at an average rate of $131,800 \mathrm{lb} / \mathrm{hr}$ with a $32 \mathrm{psig}$ well thead pressure (Figure 11). During the 186-hour flow test, samples of the steam and water were collected every hour. All brine and steam condensate samples were tested for tritium, carbohydrate (CHO), total organic carbon (TOC), ammonium $\left(\mathrm{NH}_{4}\right)$ and nitrate $\left(\mathrm{NO}_{3}\right)$, and randomly selected samples were tested for polymer residues and other tracers (Table 13). Figures 12 
and 13 present plots of tracer concentration (polymer and tritium) versus volume of fluid produced. The samples were also tested for tracers present in the lower interval frac fluid. None of these tracers were found in the production samples indicating no communication with the lower zone frac fluid.

The degradation of the polymers can be investigated by observing the CHO content of the fluids. The polymers used in the frac fluids are essentially 100 percent $\mathrm{CHO}$ and will degrade to noncarbohydrate carbon material. The total polymer can still be monitored by observing the TOC content of the fluid. The carbon content of the fluid cannot normally be degraded under these conditions and will only be reduced by dilution with the formation waters. The amount of frac fluid left in the formation can be calculated by a material balance based on the TOC analysis.

The proposed frac program called for a polymer concentration of about $1,440 \mathrm{ppm}(12 \mathrm{lb} / 1000 \mathrm{gal})$ which would yield a TOC concentration of $576 \mathrm{ppm}$ in the initial fracture fluid. Using Figure 12 to calculate the quantity of TOC produced and comparing this value to the assumed injected TOC content gives a 20 percent return of the fracture fluid. The actual measured polymer concentration, however, was 3,265 ppm polymer instead of the planned 1,440 ppm. Comparing this concentration to the TOC produced yields a return of fracture fluid of 40 percent. This larger value is further confirmed by the tritium return from the upper zone. The plot of the tritium concentration versus the cumulative production, shown in Figure 13, indicates that the frac fluid content of 
the produced water drops rapidiy but is still being produced at the end of the test. A material balance based on the data in Figure 13 shows that 65 percent of the frac fluid water (tritium) was recovered from the formation. The difference in trituim and polymer return (i.e., 65 percent and 40 percent respectively) indicates some phase separation in the formation with retention of part of the polymer.

As polymer degrades, the CHO concentration of the solution decreases. If the decomposition product is to a water soluble noncarbohydrate containing organic materials, the TOC concentration of the solution will remain constant as the CHO concentration decreases. This results in a TOC/CHO ratio which can be utilized to monitor the frac polymer degradation.

The TOC/CHO ratios in the aqueous solution of these polymers should be about 0.4 . The initial flow samples taken immediately after the frac job had TOC/CHO ratios of $0.45,0.40$, and 0.42 (Table 10). These ratios show little if any polymer degradation. Nineteen days after the fracture job, sample No. 1 in Table 13 shows a ratio of 3.28 , indicating considerable polymer degradation. Table 13 illustrates the increase of polymer degradation throughout the flow test until the 31 st of July (CHO equals zero 25 days after the frac job with a cumulative produced volume of about 17 million pounds of fluid) when no more polymer was produced, indicating that the polymer had degraded totally to noncarbohydrate materials. However, the polymer residue was still being produced as indicated by the high TOC content $(200 \mathrm{ppm})$ in the samples. 
During the production test of the upper and intermediate intervals, Lawrence Berkeley Laboratory (LBL) attempted to run their spinner and pressure tools, but the equipment malfunctioned and forced termination of the testing of their equipment. A downhole temperature tool was successfully run (Figure 14). The unflashed fluid temperature was $315^{\circ} \mathrm{F}$ at 4,900 feet.

LBL also obtained three unflashed fiuid samples at 5,100 feet, 5,300 feet and 6,300 feet. Vetter Research analyzed these samples for tracer content (Table 14). A review of the attempt to isolate the upper from the intermediate zone for stimulation shows that the upper interval was not completely segregated. A small quantity of tritium tracer (12 $\mathrm{dpm} / \mathrm{ml}$ ) was found in the 6,300-foot unflashed sample; however, as would be expected, the 5,300-foot and 5,100-foot samples contained a high concentration of tritium (Table 14). The temperature survey (Figure 10) also supports the contention that the two intervals had not been completely segregated during Experiment No. 4. The ammonium and nitrate analyses show that there was no communication with the lower frac zone (Experiment No. 3).

The well was shut in after 186 hours of production and the pressure buildup recorded (Table 15). A Horner-type calculation indicated that the upper and intermediate intervals had a combined permeabilitythickness of 9,427 md-ft. Figure 15 illustrates the pressure buildup data. This represents an overall increase in $k h$ for the upper and intermediate zones of 77 percent. Because the stimulation treatment 
affected both the upper and intermediate intervals, the proration of the productivity increase for the upper interval was deferred until the entire wellbore was tested.

\section{B. Post-Stimulation Evaluation - Experiment No. 3}

Following the flow test on the upper and intermediate zones, the next operation was to clean out the wellbore to 6,850 feet and uncover the lower interval. This type of cleanout may be accomplished in a number of ways, e.g., by bailing or by a combination of circulating the sand up from the bottom with tubing and flowing it out of the well. The latter method using continuous coil tubing was selected on the basis of savings in rig costs. Continuous coil tubing was run into the well to the top of the sand $f i l l$ and a nitrogen-water mixture was injected down the tubing to jet the sand off-bottom and flow it to the surface using the natural flow of fluids from the well. This technique is commonly applied in the oil industry and has been utilized successfully in the East Mesa field. However, during this job the tubing parted, leaving 5,100 feet of tubing in the hole.

A workover rig was moved in and a three-month fishing operation followed. The fishing operation was completed on November 26, 1980, and the sand was cleaned out to 6,979 feet. Some frac and formation sand was produced into the wellbore during the operation. Damage to the formation at the wellbore could have occurred as a result of the fishing, milling, and cleanout operations. Due to the many trips of

tubing required to recover the fish and clean out the well, the surging 
of fluids in the wellbore could have forced foreign particles such as pipe dope, pipe scale, metal particles, and other solids into the formation.

Following the fishing operations, the workover rig was moved off and the well placed on production. The well was flowed for 185 hours at an average rate of $197,900 \mathrm{lb} / \mathrm{hr}$ (Figure 16). The wellhead pressure was maintained at about 27 psig. Spinner and continuous temperature surveys were run to 6,939 feet (Table 16 and Figure 17). The upper interval (Experiment No. 4) produced 47 percent $(93,000 \mathrm{lb} / \mathrm{hr}$ ) of the fluids while the lower interval produced 25 percent $(49,500 \mathrm{lb} / \mathrm{hr})$ of the fluid. The unflashed fluid temperature was $331^{\circ} \mathrm{F}$ at 4,900 feet. The increase in fluid temperature may be directly attributed to the increased production of hotter fluid from the lower interval. The overall fluid production capability had increased 114 percent over the pre-stimulation productivity.

The tracer analyses of this flow test were primarily based upon TOC, CHO, tritium, iodide, ammonium, and nitrate concentrations (Tabie 17). The half-lives of the radioactive jodide 131 and sulfur 35 , are 8 and 87 days, respectively. As a result of the prolonged well work before flow of the lower interval, these tracers were undetectable. A plot of TOC and $\mathrm{CHO}$ concentrations is presented in Figure 18. Analysis of the TOC is complicated in that both the upper-intermediate and lower treated intervals contained TOC from the frac treatments. 
The tritium (Figure 19) was produced from the upper and intermediate intervals, as it was only added as a tracer in Experiment No. 4. Based upon the relative concentrations of tritium found in the second flow test, the upper-intermediate interval is contributing about one percent of the returned frac fluid. A material balance, corrected for the one percent contribution of the upper-intermediate interval, gives a value of ten percent return of the polymer injected into the lower zone fracture. Little, if any, lower zone tracer was observed, indicating substantial dilution in the formation between the time of the frac job (July 1980) and the time of the flow test (December 1980).

The ratio of the curves TOC and CHO shown in Figure 18 may be used to study the deterioration of the frac polymer. The initial ratio of TOC/CHO was about 0.5 at the time of fracture operations. At the start of the December flow test, this ratio had increased to about 6.9 . This indicates that the polymer had decomposed substantially during the three months prior to the second flow test. The CHO analysis also indicated that the polymer concentration never went to zero. For that to occur, undecomposed polymer must have still been present in the produced fluids.

The well was shut in and the pressure buildup recorded (Table 18). Figure 20 illustrates the Horner plot where the permeability-thickness was calculated to be $10,311 \mathrm{md}-\mathrm{ft}$. This represents a 38 percent increase in permeability-thickness for well 58-30 as a direct result of both stimulation experiments. 
Table 19 summarizes the productivity improvement of the upper, intermediate, and lower intervals before and after stimulation. The percent of inflow was allocated on the basis of the spinner surveys. Experiment No. 3, while giving a small percentage improvement in $\mathrm{kh}$ (19 percent), did result in a significant improvement in fluid production (84 percent) from the lower interval. As shown in Figure 17, the increased flowing fluid temperature may indicate the creation of a fracture connected to hotter fluids below the lower treatment interval.

A review of Experiment No. 4 was possible once the post-stimulation production from the entire well had been evaluated. As noted in Table 19, the upper and intermediate intervals account for 75 percent of the fluid production after the stimulation jobs. Ouring the upper zone frac evaluation flow test, the upper interval, therefore, produced 63 percent of the total fluid, assuming that the ratio of production between these two intervals remains constant. Proration of 63 percent of the production to the upper interval results in a $k \mathrm{~h}$ value of $5,939 \mathrm{md}-\mathrm{ft}$. This would represent a 108 percent $k h$ improvement in the upper interval after stimulation Experiment No. 4. Unfortunately, extensive well work appears to have resulted in some near-wellbore damage and a drop in $\mathrm{kh}$ to $4,846 \mathrm{md}-\mathrm{ft}$, or a 70 percent increase in $\mathrm{kh}$ from the pre-stimulation condition. The intermediate interval appears to have experienced a 24 percent drop in $k h$ between the test of the upper-intermediate interval and the final post-stimulation test. 


\section{EXPERIMENT COSTS}

The total cost of rig work and fracturing expenses for Experiments Nos. 3 and 4 was $\$ 707,145$. The costs were not broken down by experiment as all materials were purchased in bulk and services were performed consecutively at one wellsite (Table 20). Of the total cost, $\$ 420,031$ was expended for fracture materials, services, and rig expenses; $\$ 34,566$ was spent for subcontractors to help design and monitor the fracture treatments. As discussed in prior sections, an unanticipated $\$ 252,548$ was expended to recover the coiled tubing dropped in the well. Costs incurred by RGI are not included in Table 20. RGI cost-shared the fishing operation with labor expenses and equipment worth approximately $\$ 50,000$. 


\section{CONCLUSIONS}

East Mesa Well 58-30 was successfully stimulated with two separate fracture treatments, a dendritic fracture and a planar fracture. The overall well permeability-thickness was improved from 7,493 md-ft to $10,311 \mathrm{md}-\mathrm{ft}$. The natural flow production of the well increased from $92,3001 \mathrm{~b} / \mathrm{hr}$ to $197,900 \mathrm{lb} / \mathrm{hr}$, or a 114 percent increase.

Mechanically, the interval for Experiment No. 3 was successfully isolated using commercially available packers. The Experiment No. 4 interval was not successfully isolated, but the failure was not related to high wellbore temperatures.

Experiment No. 3, a conventional (planar) fracture treatment, improved the lower interval $\left(6834^{\prime}-6587^{\prime}\right)$ productivity by 84 percent and the $\mathrm{kh}$ increased 19 percent. The increase in hotter fluid from this production zone lowered the flash point, decreased the downhole flowing pressure, and thus improved the overall well performance.

Experiment No. 4, a dendritic fracture treatment designed for the upper interval $\left(5256^{\prime}-4952^{\prime}\right)$ to overcome near wellbore damage in a high permeability sand, showed initial improvement (i.e., before the fishing operations) of 108 percent increase in $\mathrm{kh}$ and a 137 percent increase in productivity. Part of this improvement was lost because of wellbore damage during the cleanout operation. 
The East Mesa field experiments provided experience in the 0 stimulation of matrix-type reservoirs in the $320-350^{\circ} \mathrm{F}$ temperature range. This experience provided valuable insights for designing later, high-temperature reservoir experiments. All the stimulation techniques and materiais utilized appear to be capable of withstanding the moderate temperature geothermal environment. 


\section{$X$. REFERENCES}

1. Geothermal Reservoir Well Stimulation Project, Reservoir Selection Task, November 1979 , prepared for $0.0 . E$. by RGI under contract No. DE-AC32-79AL10563

2. Proposal for Producing Well Hydraulic Fracture Stimulation Treatments, East Mesa Field, Geothermal Reservoir Well Stimulation Program, ApriT 1980, prepared for D.O.E. by RGI under contract No. DE-AC 32-79AL10563

3. McGuire, W. J. and Sikora, V. J. "The Effect of Vertical Fractures on Wel1 Productivity," Trans AIME (1960), Vol. 219, pp. 401-403.

4. Raft River Well Stimulation Experiments, Geothermal Reservoir We1l Stimulation Program, August 1980, prepared for D.O.E. by RGI under Contract NO. DE-AC32-79ALT0563

5. Interactive Fracture Design Mode1, Geothermal Reservoir Well Stimulation Program, May 1980, prepared for D.O.E. by RGI under Contract NO. DE-AC32-79AL10563. 


\section{TABLE 1 \\ EAST MESA 58-30 \\ PRODUCTION LOG RESULTS (PRE-STIMULATION) \\ $\%$ ZONAL INFLOW \\ SPINNER TEMPERATURE \\ $(6-19-80) \quad(6-19-80)$}

INTERVAL

A. UPPER INTERVAL

$4952^{\prime}-4957^{\prime}$

$5105^{\prime} \cdot 5200^{\prime}$

$\begin{array}{ll}10 & 2 \\ \frac{28}{38} \% & \frac{36}{38} \%\end{array}$

B. INTERMEDIATE INTERVAL

$5469^{\prime}$ - 5497'

$5600^{\circ} \cdot 5650^{\circ}$

$5785^{\prime} \cdot 5800^{\prime}$

$5870^{\circ} \cdot 5880^{\prime}$

$6326^{\prime} \cdot 6351^{\prime}$

$6411^{\prime} \cdot 6467^{\prime}$

$6496^{\circ} \cdot 6541^{\circ}$ $95^{\prime}$

$28^{\prime}$

$50^{\circ}$

$15^{\prime}$

$10^{\circ}$

$25^{\prime}$

$50^{\circ}$

$45^{\prime}$

C. LOWER INTERVAL

$6637^{\prime}-6667^{\prime}$

$6702^{\circ}-6712^{\prime}$

$6767^{\prime}-6777^{\prime}$ $30^{\circ}$
$10^{\circ}$
$10^{\circ}$

\begin{tabular}{c}
11 \\
8 \\
10 \\
\hline $29 \%$
\end{tabular}

5

10

$\frac{6}{21 \%}$

NOTE: SPINNER DATA UTILIZED FOR ALL INFLOW CALCULATIONS.

361577 
TABLE 2

\section{EAST MESA 58-30 PRE-STIMULATION PRESSURE BUILOUP TEST \\ FOR ENTIRE WELLBORE}

Depth:

Pressure Element:

Interval Tested:

Prior Flow Period:

Average Total Flow Rate:

Date tested:

Shut-in Time

(hrs)

0

0.28

0.3

0.5

1.0

2.0

5.0

10.0

15.0

20.0

25.0

28.0

30.0

35.0

37.0

41.1

43.1

44.1 $4900^{\prime}$

43601

$4952^{\prime}-6936^{\prime}$

163 hours

$92,300 \mathrm{lb} / \mathrm{hr}$

$6 / 17-24 / 80$

Pressure o $4900^{\prime}$

(psig)

1943

1956

1969

1986

1993

2000

2009

2020

2026

2029

2032

2038

2039

2040

2042

2042

2046

2046 


\section{TABLE 3}

EAST MESA 58-30 CONVENTIONAL (PLANAR) FRACTURE TREATMENT

$\begin{array}{clc} & \text { Amount of } \\ \text { Fluid } & \text { Cumulative } \\ \text { Item } & \text { Pumped (BBL) } & \text { Fluid (BBL }\end{array}$

Pumped (BBL) Fluid (BBL)

100

100

800

900

530

Eroding fine

sand injected

Pad to place

fine sand

Resin-coated sand injected

Frac sand

injected

Frac sand

injected

Resin-coated sand injected

Flush to perforations
165

530

2110

165

2775

360

2635

180

2815

2275

rosslinked gel and FLA

2 ppg 20/40-mesh resin-coated sand in crosslinked gel. No FLA.

2 ppg 20/40-mesh frac sand

3 ppg 20/40-mesh frac sand

3 ppg 20/40-mesh resin-coated sand in crosslinked gel

Pit water 
TABLE 4

\section{EAST MESA 58-30 (DEEP ZONE) CONVENTIONAL (PLANAR) FRACTURE TREATMENT SUMMARY 7/3/80}

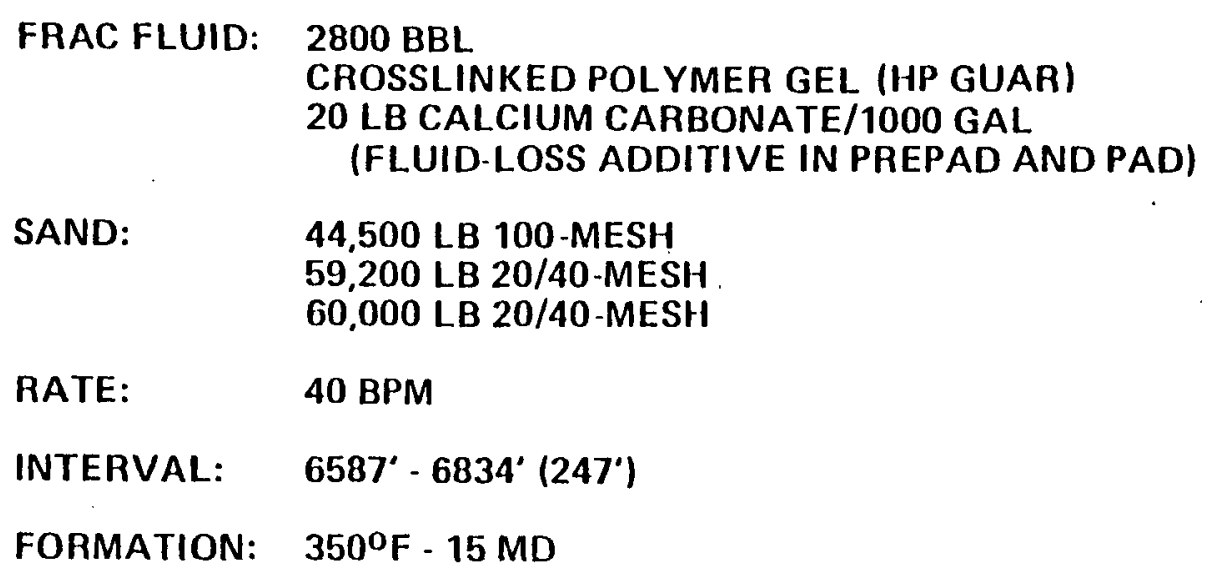


TABLE 5

ANALYSIS OF FLUIDS USED FOR EXPERIMENT NO. 3

Sample

\begin{tabular}{|c|c|c|}
\hline \multicolumn{3}{|c|}{ ppm } \\
\hline Carbohydrate & Carbon & $\mathrm{NH}_{4}$ \\
\hline 7742 & 3871 & 88.0 \\
\hline 7323 & 3662 & -- \\
\hline 6294 & 3147 & 90.0 \\
\hline 7313 & 3657 & -- \\
\hline 8513 & 4257 & --- \\
\hline 7237 & 3619 & 93.0 \\
\hline 7404 & 3702 & \\
\hline
\end{tabular}


EAST MESA 58-30 EXPERIMENT NO. 3 (LOWER ZONE)

PLANAR FRACTURE LENGTH

$$
\begin{aligned}
& Q=40 \mathrm{BPM} \\
& H=250 \mathrm{ft} \\
& C=0.006 \mathrm{ft} / \sqrt{\mathrm{min}} \\
& \mu=25 \mathrm{cP}
\end{aligned}
$$

\begin{tabular}{lcccc}
\hline $\begin{array}{l}\text { WIDTH } \\
\left(I_{\mathrm{n}}\right)\end{array}$ & $\begin{array}{c}\text { LENGTH } \\
(\mathrm{Ft})\end{array}$ & $\begin{array}{l}\text { VOLUME } \\
(\text { Cu Ft) }\end{array}$ & $\begin{array}{c}\text { EFF } \\
(\%)\end{array}$ & $\begin{array}{c}\text { TIME } \\
\text { (Min) }\end{array}$ \\
\hline 0.14 & 43.28 & 246.16 & 21.92 & 5.00 \\
0.15 & 64.34 & 404.06 & 17.99 & 10.00 \\
0.16 & 80.51 & 534.70 & 15.87 & 15.00 \\
0.17 & 94.10 & 649.85 & 14.47 & 20.00 \\
0.17 & 106.15 & 755.51 & 13.46 & 25.00 \\
0.18 & 117.25 & 855.48 & 12.70 & 30.00 \\
0.18 & 127.31 & 948.26 & 12.06 & 35.00 \\
0.18 & 136.72 & 1036.58 & 11.54 & 40.00 \\
0.18 & 145.56 & 1121.10 & 11.09 & 45.00 \\
0.19 & 153.95 & 1202.37 & 10.71 & 50.00 \\
0.19 & 161.83 & 1280.83 & 10.37 & 55.00 \\
0.19 & 169.57 & 1356.79 & 10.07 & 60.00 \\
0.19 & 176.90 & 1430.54 & 9.80 & 65.00 \\
0.20 & 183.97 & 1502.30 & 9.56 & 70.00 \\
& & & & \\
\hline
\end{tabular}


TABLE 7

TYPICAI STAGE OF DENDRITIC TREATMENT

\begin{tabular}{|c|c|c|c|}
\hline Item & $\frac{\text { Fluid Vol }}{(B B L)}$ & $\begin{array}{l}\text { Cumulative } \\
\text { Fluld Vol } \\
\text { (BBL) }\end{array}$ & Comments \\
\hline Pad & 700 & 700 & $\begin{array}{l}\text { Light gel } \\
\text { plus fluid-loss } \\
\text { additive (FLA) }\end{array}$ \\
\hline Sand slug & 28 & 728 & $\begin{array}{l}4 \mathrm{lb} / \mathrm{gal} \\
100 \text { mesh sand }\end{array}$ \\
\hline $\mathrm{Pad}$ & 500 & 1228 & Gel and FLA \\
\hline Sand slug & 28 & 1256 & $\begin{array}{l}41 \mathrm{~b} / \mathrm{gal} \\
100 \text { mesh sand }\end{array}$ \\
\hline Pad & 300 & 1556 & Gel and FLA \\
\hline $\begin{array}{l}\text { Shut down } \\
\text { flow back }\end{array}$ & - & $\begin{array}{l}1556 \\
1556\end{array}$ & $\begin{array}{l}(2 \mathrm{~min}) \\
(30 \mathrm{sec})\end{array}$ \\
\hline Pad & 300 & 1856 & Gel and FLA \\
\hline $\begin{array}{l}\text { Shut down } \\
\text { flow back }\end{array}$ & - & $\begin{array}{l}1856 \\
1856\end{array}$ & $\begin{array}{l}(2 \mathrm{~min}) \\
(30 \mathrm{sec})\end{array}$ \\
\hline
\end{tabular}




\section{TABLE 8}

EAST MESA 58-30 (SHALLOW ZONE)

\section{5-STAGE DENDRITIC FRACTURE TREATMENT SUMMARY 7/6/80}

FRAC FLUID: $\quad 10,300 \mathrm{BBL}$

10 LB HP GUAR/1000 GAL

2 LB XC POL YMER/1000 GAL

20 LB CALCIUM CARBONATE/1000 GAL

(FLUID-LOSS ADDITIVE)

SAND: $\quad 44,000$ LB $100-M E S H$

RATE: $\quad 48 \mathrm{BPM}$

INTERVAL: $\quad 4952^{\prime}-5256^{\prime}\left(304^{\prime}\right)$

FORMATION: $325^{\circ} \mathrm{F}-50 \mathrm{MD}$ 
TABLE 9

ANAIYSIS OF FRAC FLUID SAMPLES
FROM BLENDER BEFORE INJECTION, EXPERIMENT NO. 4 - JULY 6, 1980

Stage No.

1

2

3

4

5

Average

\section{Carbohydrate ( $\mathrm{CHO}$ ), ppm}

4774

4557

2408

2744

2239

3265
Carbon (TOC), PPm

1909

2085

939

1098

$\underline{963}$

1367 
TABLE 10

ANALYSIS OF FLOWBACK SAMPLES AFTER

EXPERIMENT NO. 4 - JULY 6, 1980

\begin{tabular}{|c|c|c|c|c|}
\hline Time Flowed & CHO, PPm & Toc, ppm & $3 \mathrm{H}, \mathrm{dpm} / \mathrm{ml}$ & $\mathrm{TOC} / \mathrm{CHO}$ \\
\hline $26 \mathrm{~min}$. & 2544 & 2245 & 6287 & 0.45 \\
\hline 30 min. & 2779 & 1112 & 6971 & 0.40 \\
\hline 60 min. & 2457 & 1032 & 6285 & 0.42 \\
\hline Average & 2593 & 1096 & 6514 & \\
\hline
\end{tabular}


TABLE 11

EAST MESA 58-30 EXPERIMENT NO. 4 (UPPER ZONE)

DENDRITIC FRACTURE LENGTHS

$$
\begin{aligned}
Q & =50 \mathrm{BPM} \\
\mathrm{H} & =300 \mathrm{ft} \\
\mathrm{C} & =0.01 \mathrm{ft} / \sqrt{\mathrm{min}} \\
\mu & =2 \mathrm{cp}
\end{aligned}
$$

\begin{tabular}{llllr}
\hline $\begin{array}{l}\text { WIDTH } \\
(\mathrm{In})\end{array}$ & $\begin{array}{c}\text { LENGTH } \\
(\mathrm{ft})\end{array}$ & $\begin{array}{l}\text { VOLUME } \\
(\text { cu } \mathrm{ft})\end{array}$ & $\begin{array}{l}\text { EFF. } \\
(\%)\end{array}$ & $\begin{array}{l}\text { TIME } \\
(\mathrm{min})\end{array}$ \\
\hline 0.032 & 32.5 & 51.7 & 3.7 & 5 \\
0.038 & 46.1 & 87.4 & 3.1 & 10 \\
0.042 & 56.6 & 118.9 & 2.8 & 15 \\
0.045 & 65.3 & 147.7 & 2.6 & 20 \\
0.048 & 73.3 & 174.9 & 2.5 & 25 \\
0.050 & 80.3 & 200.7 & 2.4 & 30 \\
0.052 & 86.8 & 225.5 & 2.3 & 35 \\
0.054 & 92.8 & 249.4 & 2.2 & 40 \\
\hline
\end{tabular}


TABLE 12

TEMPERATURE-DISTANCE RELATIONSHIP IN FRACTURES

EXPERIMENT NO. 4

\begin{tabular}{cr} 
Depth of Fracture, ft. & Temperature, ${ }^{\circ} \mathrm{F}$ \\
\hline 0.00 & 100.00 \\
4.64 & 106.26 \\
9.28 & 113.19 \\
13.92 & 120.86 \\
18.56 & 129.33 \\
23.20 & 138.68 \\
27.85 & 148.99 \\
32.49 & 160.33 \\
37.13 & 172.78 \\
41.77 & 186.39 \\
46.41 & 201.19 \\
51.05 & 217.18 \\
55.69 & 234.27 \\
60.33 & 252.26 \\
64.97 & 270.77 \\
69.61 & 289.14 \\
74.25 & 306.32 \\
78.90 & 320.79 \\
83.54 & 330.66 \\
88.18 & 334.68 \\
92.82 & 335.00
\end{tabular}




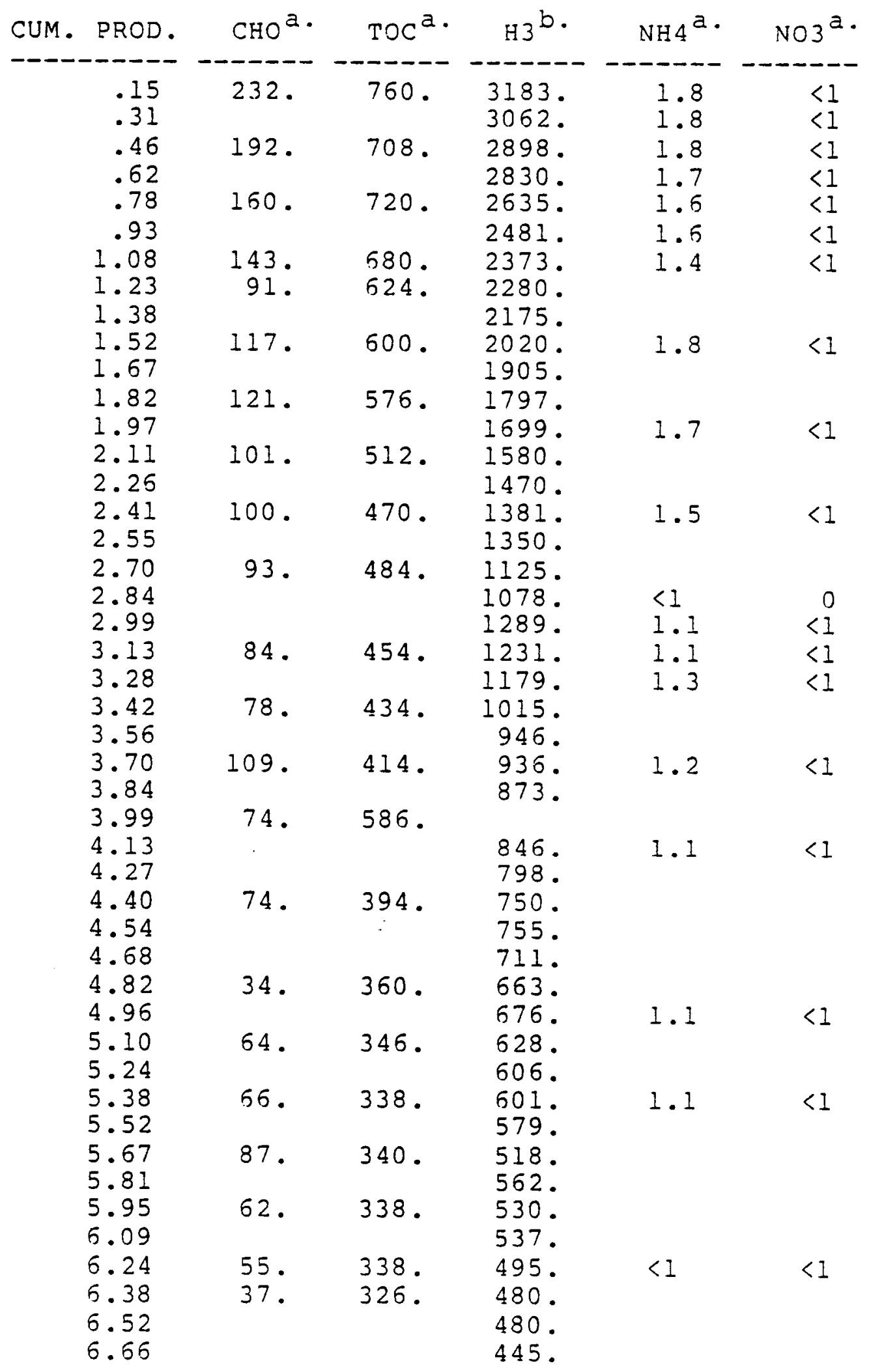

Cumulative production expressed in millions of pounds. $N / R$ indicates not requested to be analyzed. 
Table 13 (continued)

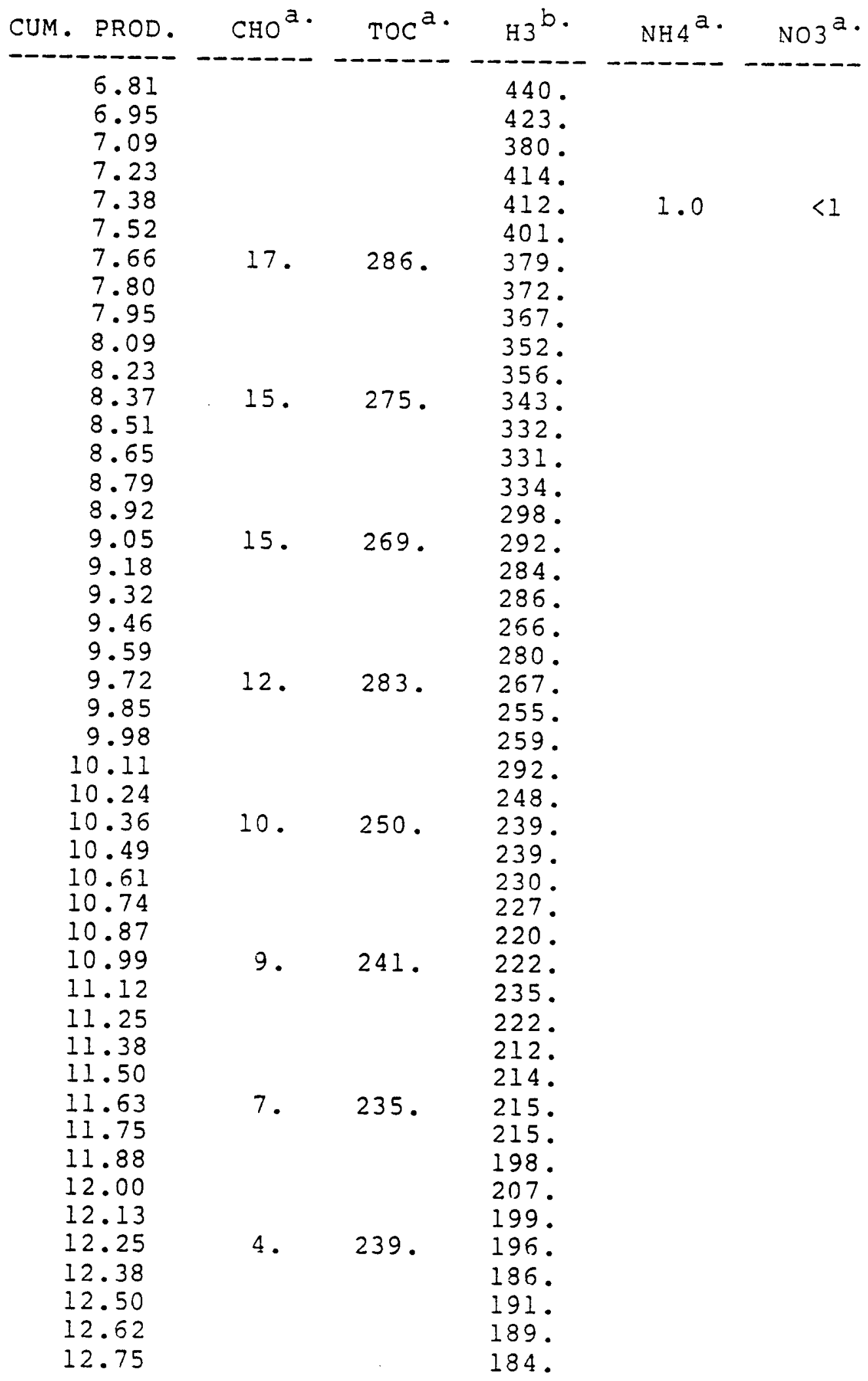

Cumulative production expressed in millions of pounds. $N / R$ indicates not requested to be analyzed. 
Table 13 (continued)

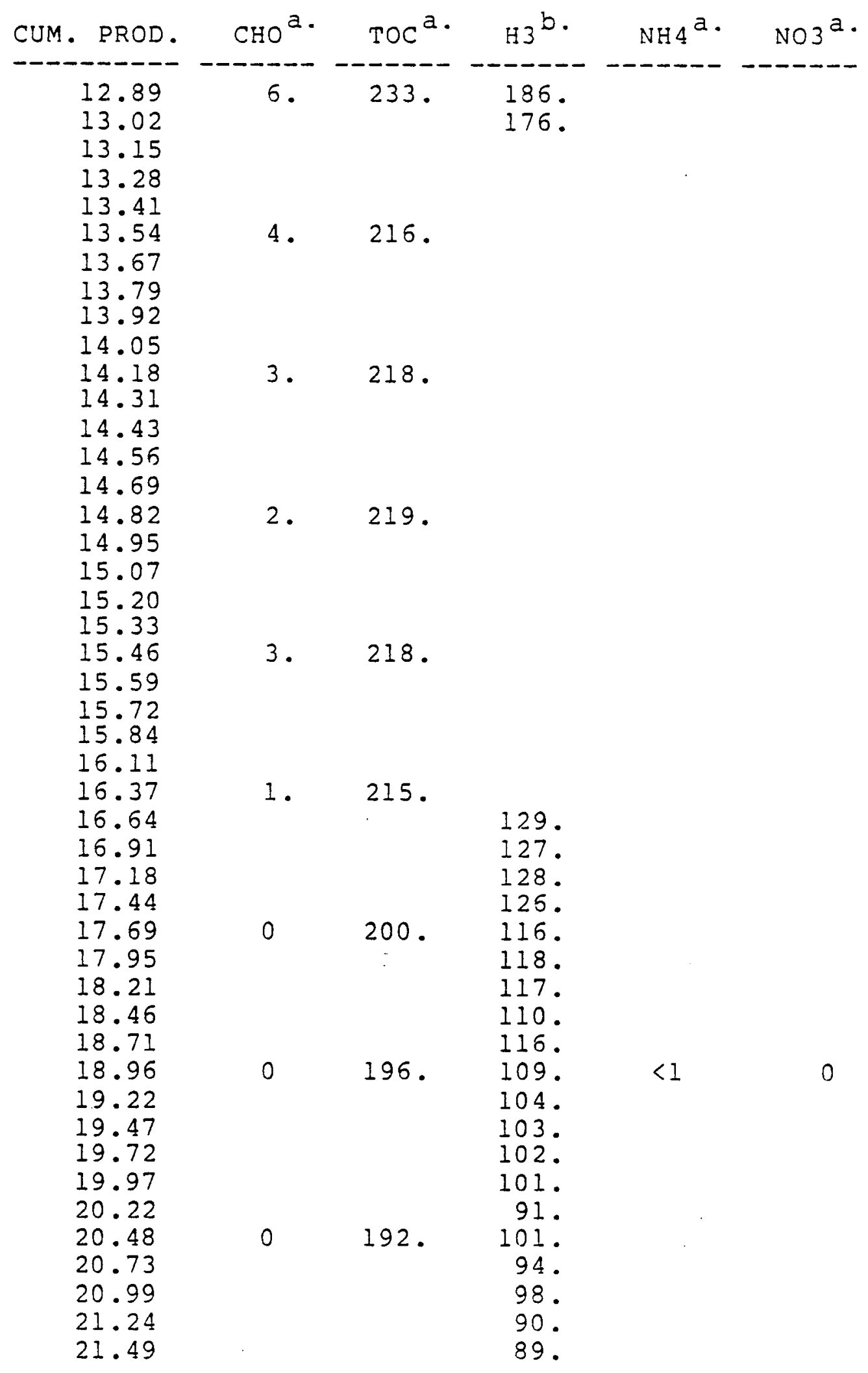

Cumulative production expressed in millions of pounds. $N / R$ indicates not requested to be analyzed. 
Table 13 (continued)

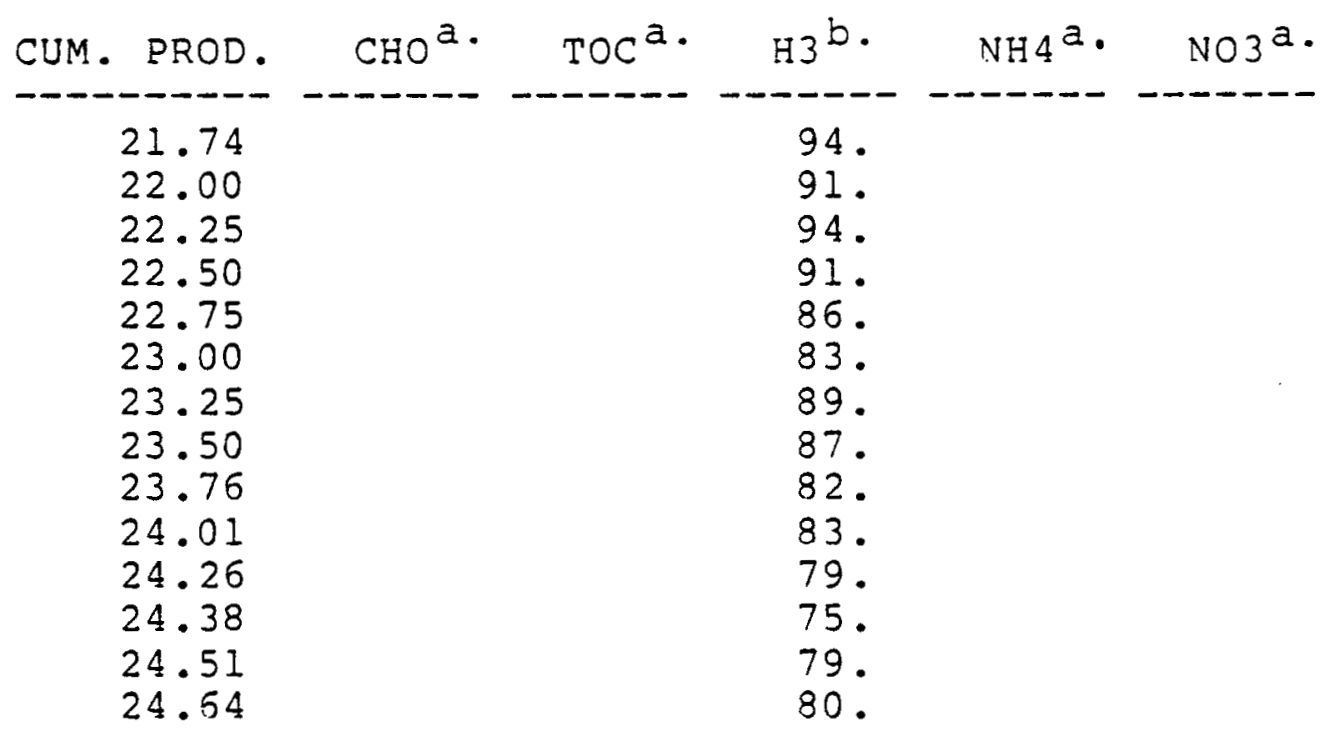

a. Polymer (CHO), total organic carbon (TOC), ammonium (NH4), nitrate (NO3), and iodide (I) expressed as mg/l (ie., ppm).

b. Tritium (H3) expressed as disintegrations per minute per milliliter.

c. Radioactive iodide (I131) expressed as disintegrations per minute per liter.

Cumulative production expressed in millions of pounds. $N / R$ indicates not requested to be analyzed. 


\section{TABLE 14}

DOWNHOLE SAMPLES TAKEN JULY 29, 1980

\begin{tabular}{lccc}
$\begin{array}{l}\text { Depth } \\
(\mathrm{ft})\end{array}$ & $\begin{array}{c}3 \mathrm{H} \\
(\mathrm{dpm} / \mathrm{ml})\end{array}$ & $\begin{array}{c}\mathrm{NH}_{4} \\
(\mathrm{ppm})\end{array}$ & $\begin{array}{c}\mathrm{NO}_{3} \\
(\mathrm{ppm})\end{array}$ \\
\cline { 2 - 2 } & 102 & $\underline{5}$ & 0.15 \\
5400 & 172 & 0.7 & 0.22 \\
6300 & 12 & 2.14 & 0.90
\end{tabular}


TABLE 15

EAST MESA 58-30 PRESSURE BUILDUP DATA
UPPER AND INTERMEDIATE ZONES OPEN

Depth:

Interval Tested:

Prior Flow Period:

Average Total

Flow Rate:

Date Tested:

Time

(hrs)

0

0.17

0.33

0.5

0.67

0.83

1.0

2.0

3.0

4.0

5.0

10.0

15.0

18.0

21.0

46.0 $4900^{\prime}$

$4952^{\prime}-6551^{\prime}$

186 hrs

$131,8001 \mathrm{~b} / \mathrm{hr}$

$7 / 25-8 / 2 / 80$

Pressure

(psig)

1937

1965

1981

1988

1991

1992

1996

2002

2009

2012

2015

2023

2030

2034

2036

2054 


\section{TABLE 16 \\ EAST MESA 58-30 \\ PRODUCTION LOG RESULTS (POST-STIMULATION)}

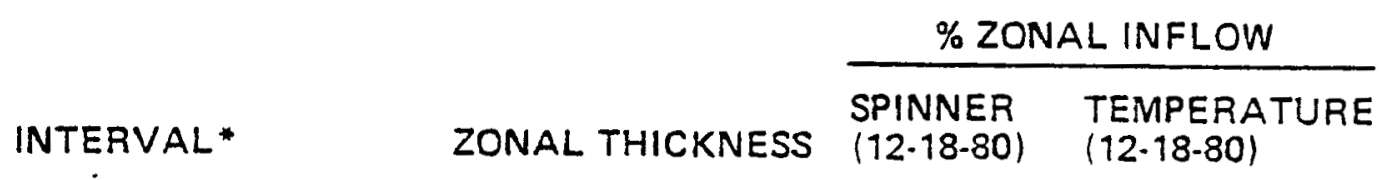

A. UPPER INTERVAL

$5139^{\circ} \cdot 5214^{\prime}$

$75^{\prime}$

$47 \%$

$42 \%$

B. INTERMEDIATE INTERVAL

$5499^{\circ} \cdot 5539^{\prime}$

$5617^{\prime} \cdot 5642^{\prime}$

$5737^{\prime} \cdot 5742^{\prime}$

$5869^{\prime}-5895^{\prime}$

$6320^{\prime}-6335^{\prime}$

$40^{\circ}$

$25^{\prime}$

$26^{\circ}$

$15^{\prime}$

$\begin{array}{rr}14 & 12 \\ 3 & 4 \\ 3 & 3 \\ 5 & 2 \\ 3 & 4 \\ \frac{3}{28} \% & 25 \%\end{array}$

C. LOWER INTERVAL

$6603^{\circ} \cdot 6733^{\circ}$

$6793^{\circ} \cdot 6838^{\prime}$

$130^{\circ}$

$45^{\prime}$

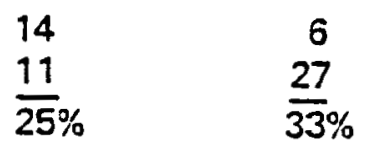

* NOTE: SPINNER DATA UTILIZED FOR ALL INFLOW CALCULATIONS.

3615736 
Part I - Samples taken during clean out operations to remove sand fill.

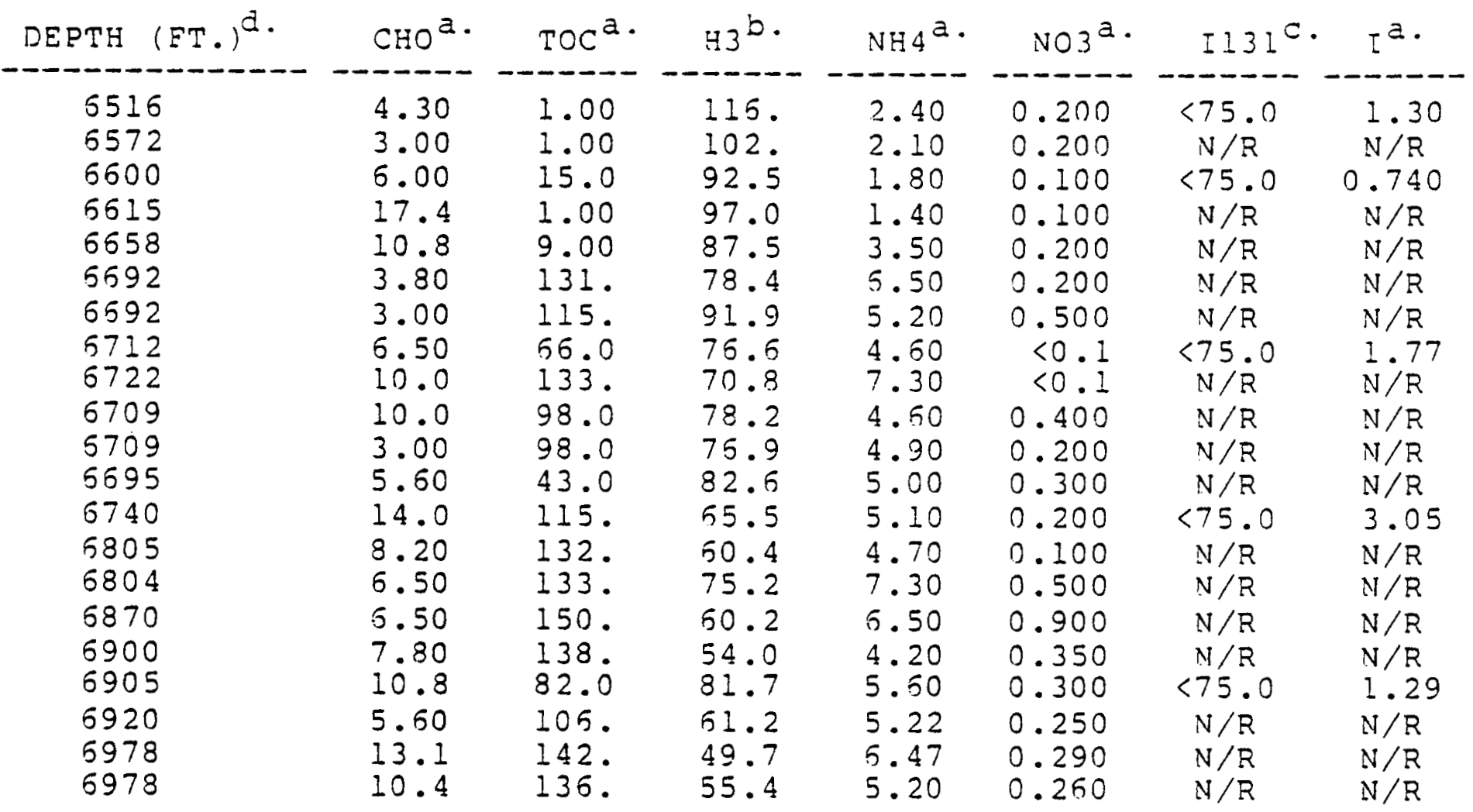

a. Polymer (CHO), total organic carbon (TOC), ammonium (NH4), nitrate (NO3), and iodide (I) expressed as mg/l (ie., pom).

b. Tritium (i3) expressed as disintegrations per minute per milliliter. Radioactive iodide (I13l) expressed as disintegrations per minute per liter.

d. Notes depth of tubing at time sample taken.

Cumulative production expressed in millions of pounds.

$N / R$ indicates not requested to be analyzed. 
Girt 2 - Samples taken during flow test.

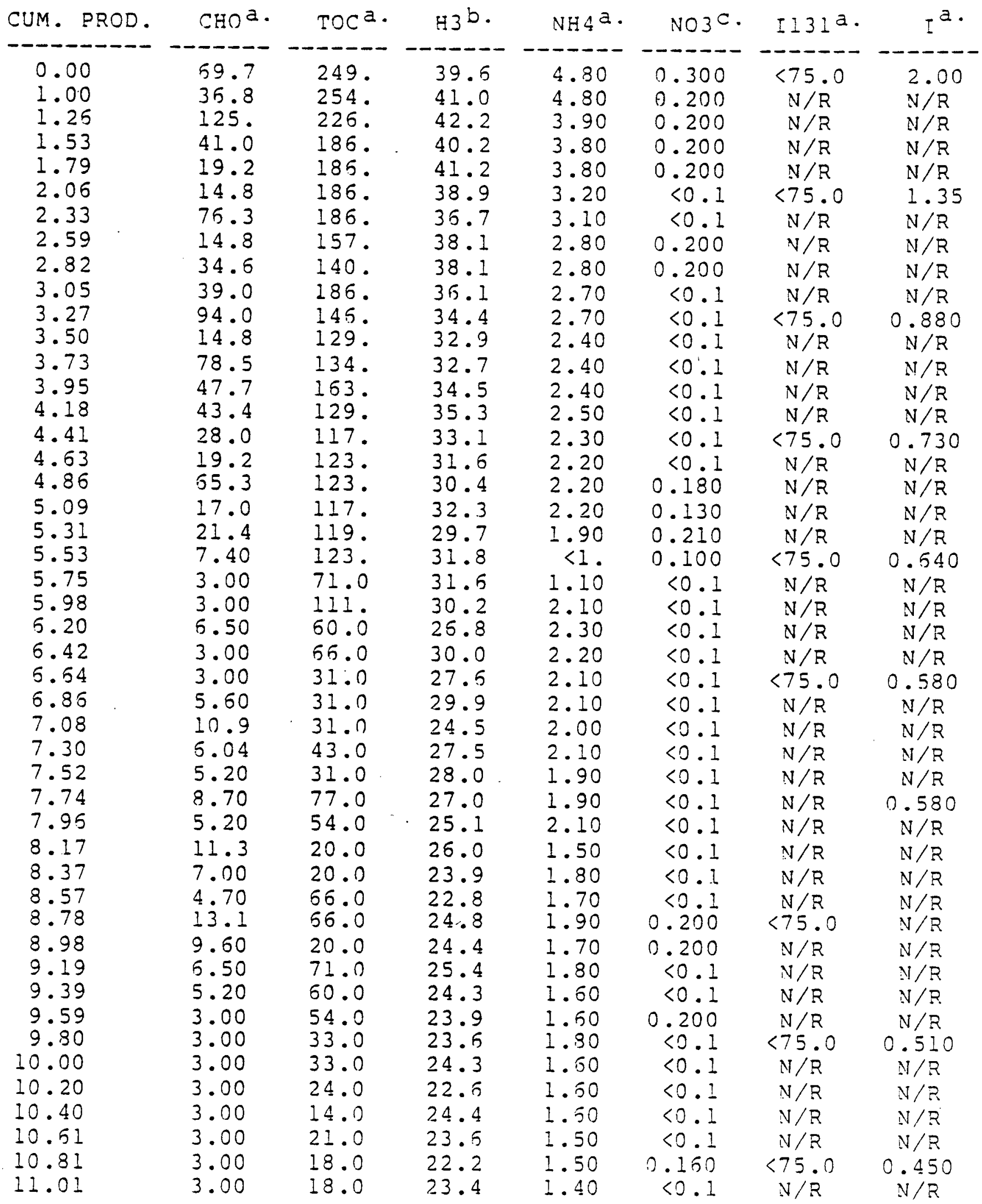

Cumulative production expressed in millions of pounds. $N / R$ indicates not requested to be analyzed. 


\begin{tabular}{|c|c|c|c|c|c|c|c|}
\hline CUM. PROD. & $\mathrm{CHO}^{\mathrm{a}}$ & TOC $^{\mathrm{a}}$ & $\mathrm{H} 3^{\mathrm{b}}$. & NH4 ${ }^{\mathrm{a}}$. & $\mathrm{NO}^{\mathrm{a}}$ & $\operatorname{I131^{\mathrm {C}}}$ & $I^{a}$. \\
\hline 11.22 & 4.70 & 18.0 & 23.9 & 1.50 & 0.100 & $N / R$ & $N / R$ \\
\hline 11.42 & 3.00 & 17.0 & 20.2 & 1.60 & $<0.1$ & $N / R$ & $N / R$ \\
\hline $11 \cdot 62$ & 3.00 & 43.0 & 19.2 & 1.40 & $<0.1$ & $N / R$ & $N / R$ \\
\hline $\begin{array}{l}11.83 \\
12.03\end{array}$ & 3.00 & 13.0 & 18.8 & $<1$. & $<0.1$ & $<75.0$ & 0.440 \\
\hline $\begin{array}{l}12.03 \\
12.23\end{array}$ & $\begin{array}{l}3.00 \\
3.00\end{array}$ & 12.0 & 19.8 & $<1$. & 0.400 & $N / R$ & $N / R$ \\
\hline & $\begin{array}{l}3.00 \\
3.00\end{array}$ & 48.0 & 20.0 & $<1$. & 0.300 & $N / R$ & $\mathrm{~N} / \mathrm{R}$ \\
\hline & 3.00 & 19.0 & 20.7 & $<1$. & 0.300 & $N / R$ & $N / R$ \\
\hline $\begin{array}{l}12.64 \\
12.84\end{array}$ & $\begin{array}{l}3.00 \\
3.00\end{array}$ & 4.00 & 19.2 & $<1$. & 0.300 & $N / R$ & $N / R$ \\
\hline 13.03 & 3.00 & $\begin{array}{l}10.0 \\
49.0\end{array}$ & $\begin{array}{l}19.0 \\
20.3\end{array}$ & $\begin{array}{l}<1 . \\
<1\end{array}$ & $\begin{array}{l}0.300 \\
0.300\end{array}$ & $\begin{array}{l}<75.0 \\
N / R\end{array}$ & 0.360 \\
\hline 13.23 & 8.20 & 31.0 & 20.0 & $<1$. & 0.300 & $\begin{array}{l}N / R \\
N / R\end{array}$ & $\begin{array}{l}N / R \\
N / R\end{array}$ \\
\hline 13.42 & 3.00 & 2.00 & 20.2 & $<1$. & 0.200 & $\mathrm{~N} / \mathrm{R}$ & $\mathrm{N} / \mathrm{R}$ \\
\hline 13.61 & 3.00 & 12.0 & 16.2 & $<1$. & 0.200 & $N / R$ & $N / R$ \\
\hline 13.81 & $N / R$ & $N / R$ & 18.6 & 1.20 & $<0.1$ & $<75.0$ & 0.330 \\
\hline 14.00 & $N / R$ & $N / R$ & 18.4 & 1.40 & $<0.1$ & $\mathrm{~N} / \mathrm{R}$ & $N / R$ \\
\hline 14.19 & 4.30 & 28.0 & 19.1 & 1.40 & $<0.1$ & $N / R$ & $N / R$ \\
\hline 14.39 & $N / R$ & $N / R$ & 16.2 & 1.40 & $<0.1$ & $N / R$ & $N / R$ \\
\hline 14.58 & $N / R$ & $N / R$ & 17.0 & $<1$. & $<0.1$ & $N / R$ & $N / R$ \\
\hline 14.77 & 5.60 & 1.00 & 19.0 & 1.20 & $<0.1$ & $<75.0$ & 0.310 \\
\hline 14.96 & $N / R$ & $N / R$ & 17.0 & 1.20 & $<0.1$ & $N / R$ & $N / R$ \\
\hline 15.16 & $N / R$ & $N / R$ & 19.2 & 1.20 & $<0.1$ & $N / R$ & $N / R$ \\
\hline 15.35 & 6.00 & 1.00 & 17.8 & $<1$. & $<0.1$ & $N / R$ & $N / R$ \\
\hline $15 \cdot 54$ & $N / R$ & $N / R$ & 17.6 & $<1$ & $<0.1$ & $N / R$ & $N / R$ \\
\hline 15.74 & $N / R$ & $N / R$ & 17.8 & 1.20 & $<0.1$ & $<75.0$ & 0.280 \\
\hline 15.93 & 10.0 & 6.00 & 19.0 & 1.30 & $<0.1$ & $N / R$ & $N / R$ \\
\hline 16.70 & $N / R$ & $N / R$ & 17.4 & 1.10 & $<0.1$ & $N / R$ & $N / R$ \\
\hline 17.47 & $N / R$ & $N / R$ & 17.7 & 1.10 & $<0.1$ & $N / R$ & $N / R$ \\
\hline 18.25 & 6.00 & 8.00 & 16.1 & 1.10 & $<0.1$ & $N / R$ & $N / R$ \\
\hline 19.02 & $N / R$ & $N / R$ & 17.1 & 1.10 & $<0.1$ & $<75.0$ & 0.210 \\
\hline 19.80 & $N / R$ & $N / R$ & 13.7 & 1.10 & 0.100 & $N / R$ & $N / R$ \\
\hline 20.58 & 4.70 & 5.00 & 16.1 & 1.10 & $<0.1$ & $N / R$ & $N / R$ \\
\hline 21.35 & $N / R$ & $N / R$ & 15.9 & $<1$. & 0.100 & $N / R$ & $N / R$ \\
\hline 22.13 & $N / R$ & $N / R$ & 15.4 & $<1$. & 0.100 & $N / R$ & $N / R$ \\
\hline 23.59 & 8.70 & 37.0 & 14.6 & 1.20 & $<0.1$ & $<75.0$ & 0.180 \\
\hline 24.32 & $N / R$ & $N / R$ & 15.4 & 1.10 & $<0.1$ & $N / R$ & $N / R$ \\
\hline 25.06 & $N / R$ & $N / R$ & 13.5 & 1.10 & $<0.1$ & $N / R$ & $N / R$ \\
\hline 25.79 & 3.00 & 135. & 14.9 & 1.10 & $<0.1$ & $N / R$ & $N / R$ \\
\hline 26.52 & $N / R$ & $N / R_{-}$ & 13.9 & $<1$. & $<0.1$ & $N / R$ & $N / R$ \\
\hline 27.26 & $N / R$ & $N / R$ & 13.9 & 1.10 & $<0.1$ & $<75.0$ & 0.150 \\
\hline 28.00 & 3.00 & 3.00 & 12.8 & 1.10 & $<0.1$ & $N / R$ & $N / R$ \\
\hline 28.75 & $N / R$ & $N / R$ & 12.9 & 1.10 & $<0.1$ & $N / R$ & $N / R$ \\
\hline & $N / R$ & $N / R$ & 12.8 & 1.10 & $<0.1$ & $N / R$ & $N / R$ \\
\hline & 3.00 & 15.0 & 11.5 & $<1$. & $<0.1$ & $N / R$ & $N / R$ \\
\hline 30.98 & $N / R$ & $\mathrm{~N} / \mathrm{R}$ & 12.1 & $<1$. & $<0.1$ & $<75.0$ & 0.130 \\
\hline .70 & $N / R$ & $N / R$ & 12.0 & 1.13 & $<0.1$ & $N / R$ & $N / R$ \\
\hline 32.42 & 3.00 & 3.00 & 12.6 & 1.01 & $<0.1$ & $N / R$ & $\mathrm{~N} / \mathrm{R}$ \\
\hline 33.14 & $N / R$ & $N / R$ & 11.3 & 1.00 & $<0.1$ & $N / R$ & $N / R$ \\
\hline
\end{tabular}

Cumulative production expressed in millions of pounds. $\mathrm{N} / \mathrm{R}$ indicates not requested to be analyzed. 
Table 17 - Part 2 (continued)

\begin{tabular}{|c|c|c|c|c|c|c|c|}
\hline IM. I & $\mathrm{CHO}^{\mathrm{a}}$. & TOC ${ }^{a}$. & $\mathrm{H} 3^{b}$. & $\mathrm{NH}_{4}{ }^{\mathrm{a}}$. & $\mathrm{NO}_{3} \mathrm{a}$. & $\operatorname{II} 31^{\circ}$. & $I^{a}$. \\
\hline 33.85 & $N / R$ & $N / R$ & 12.2 & $<1$ & $<0$. & $N / R$ & $N / R$ \\
\hline & 7.00 & 3.00 & 10.3 & $<1$. & $<0.1$ & $<75.0$ & 0.120 \\
\hline & $N / R$ & $N / R$ & 10.4 & $<1$. & $<0.1$ & $N / R$ & $\mathrm{~N} / \mathrm{R}$ \\
\hline & $N / R$ & $N / R$ & 10.0 & 1.00 & $<0.1$ & $N / R$ & $N / R$ \\
\hline 67 & 4.30 & 3.00 & 10.9 & 1.00 & $<0.1$ & $N / R$ & $N / R$ \\
\hline
\end{tabular}

a. Polymer (CHO), total organic carbon (TOC), ammonium (NH4), nitrate (NO3), and iodide (I) expressed as $\mathrm{mg} / \mathrm{l}$ (ie., ppm).

b. Tritium (H3) expressed as disintegrations per minute per milliliter. Radioactive iodide (I13l) expressed as disintegrations per minute per Iiter.

Cumulative production expressed in millions of pounds. $\mathrm{N} / \mathrm{R}$ indicates not requested to be analyzed. 
TABLE 18

EAST MESA 58-30 PRESSURE BUILDUP DATA

FOR ENTIRE WELLBORE (12/23-29/80)

Depth:

Interval Tested:

Prior Flow Period:

Average Total

Flow Rate:

Date Tested: $4900^{\prime}$

$4952^{\prime}-6939^{\prime}$

185 hrs

$197,9001 \mathrm{~b} / \mathrm{hr}$

$12 / 15-23 / 80$

\begin{tabular}{l}
$\begin{array}{l}\text { Time } \\
\text { (hrs) }\end{array}$ \\
\hline 0 \\
0.07 \\
0.08 \\
0.17 \\
0.25 \\
0.33 \\
0.42 \\
0.5 \\
0.75 \\
1.0 \\
1.5 \\
2.0 \\
4.0 \\
5.0 \\
10.0 \\
20.0 \\
30.0 \\
40.0 \\
144.0
\end{tabular}

Pressure

(psig)

1898

1916

1929

1944

1955

1960

1966

1969

1974

1980

1987

1992

2004

2009

2025

2040

2049

2047

2062 


\title{
TABLE 19
}

\section{EAST MESA 58-30}

\section{SUMMARY OF PRODUCTION TEST DATA}

\author{
UPPER \\ ZONE FRAC POST- \\ PRE-STIMULATION EVALUATION* STIMULATION
}

\begin{tabular}{|c|c|c|c|}
\hline \multicolumn{4}{|c|}{$\begin{array}{l}\text { UPPER INTERVAL - EXPERIMENT NO. } 4 \\
\left(4952^{\prime}-5266^{\prime}\right)\end{array}$} \\
\hline $\begin{array}{l}\% \text { INFLOW } \\
\text { kh (md-ft) }\end{array}$ & $\begin{array}{l}38 \\
2848\end{array}$ & $\begin{array}{l}63^{* *} \\
5939\end{array}$ & $\begin{array}{l}47 \\
4846\end{array}$ \\
\hline \multicolumn{4}{|c|}{$\begin{array}{l}\text { INTERMEDIATE INTERVAL } \\
\left(5266^{\prime}-6587^{\prime}\right)\end{array}$} \\
\hline $\begin{array}{l}\% \text { INFLOW } \\
\text { kh (md-ft) }\end{array}$ & $\begin{array}{l}33 \\
2472\end{array}$ & $\begin{array}{l}37 * * \\
\mathbf{3 4 8 8}\end{array}$ & $\begin{array}{l}28 \\
2887\end{array}$ \\
\hline \multicolumn{4}{|c|}{$\begin{array}{l}\text { LOWER INTERVAL - EXPERIMENT NO. } 3 \\
\left(6587^{\circ}-6834^{\prime}\right)\end{array}$} \\
\hline $\begin{array}{l}\% \text { INFLOW } \\
k h(\mathrm{md} \cdot \mathrm{ft})\end{array}$ & $\begin{array}{l}29 \\
2173\end{array}$ & $\bar{Z}$ & $\begin{array}{l}25 \\
2578\end{array}$ \\
\hline \multicolumn{4}{|l|}{$\begin{array}{l}\text { TOTAL COMPLETION } \\
\left(4952^{\circ}-6919^{\prime}\right)\end{array}$} \\
\hline $\begin{array}{l}\text { kh }(\text { ind-ft) } \\
\text { Q } \mid \mathrm{b} / \mathrm{hr} \\
\mathrm{T} @ 4900^{\circ}\left({ }^{\circ} \mathrm{F}\right)\end{array}$ & $\begin{array}{l}7493 \\
92,300 \\
326\end{array}$ & $\begin{array}{l}9427 \\
131,800 \\
315\end{array}$ & $\begin{array}{l}10,311 \\
197,900 \\
331 i\end{array}$ \\
\hline
\end{tabular}

'ONLY INTERVAL 4952' TO 6551' OPEN TO FLOW

* "BASED UPON POST-STIMULATION RATIOS OF PRODUCTION 
I. Experiment Expenses

A. Rig expenses

B. Fracture materials and service

C. Tools, rentals and service

D. Transportation

$\$ 74,400$

257,118

77,083

16,430

420,031

E. Subcontractors

1. Vetter

2. Maurer

7,395

3. Consultants and miscellaneous

21,637

5,534

34,566

II. Additional Fishing Expenses

252,548

Total

707,145 
FIGURE 1

\section{LOCATION OF EAST MESA 58-30}

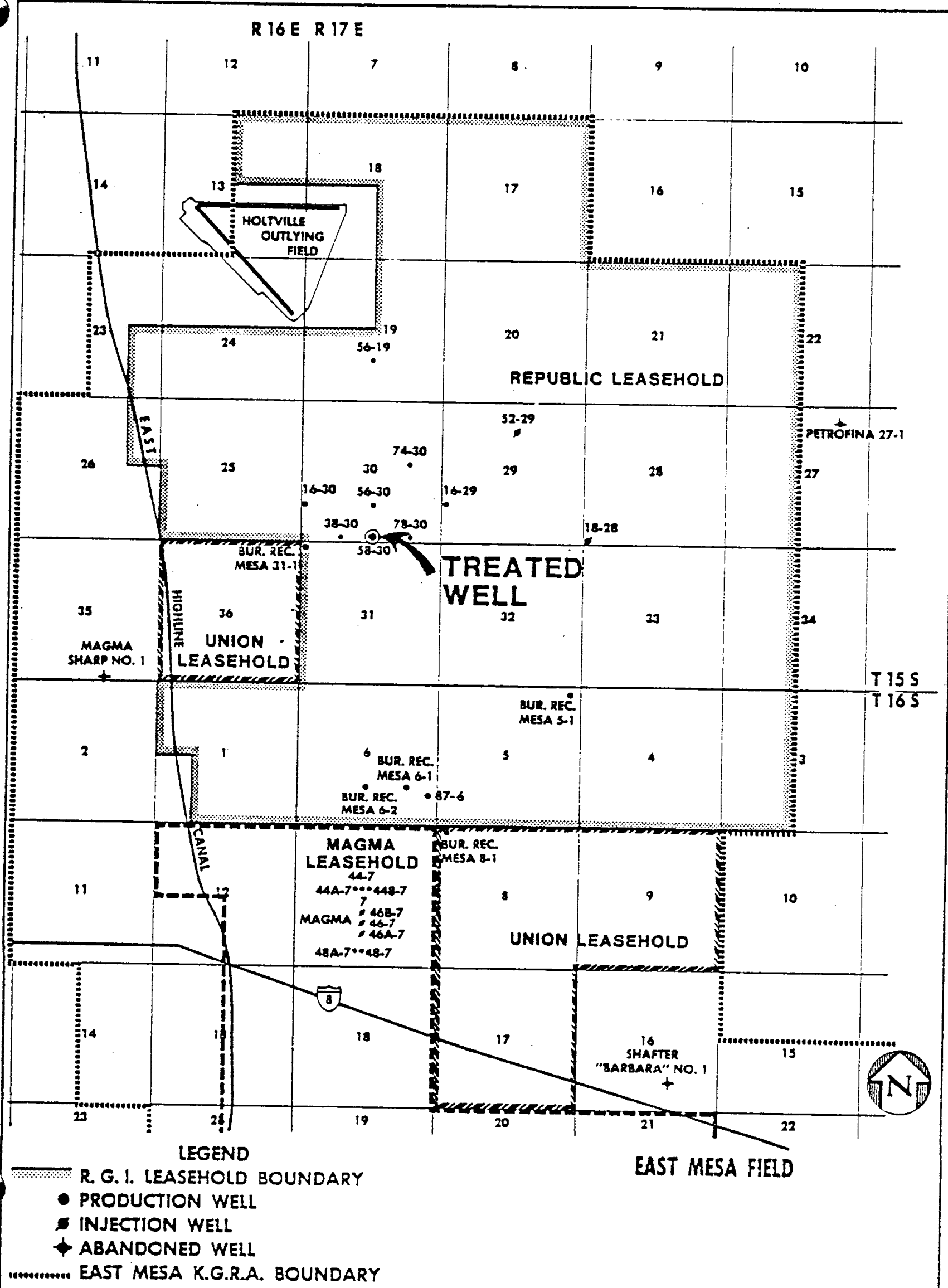




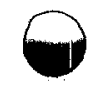

\section{FIGURE 2 \\ COMPLETION DETAIL \\ EAST MESA 58-30}

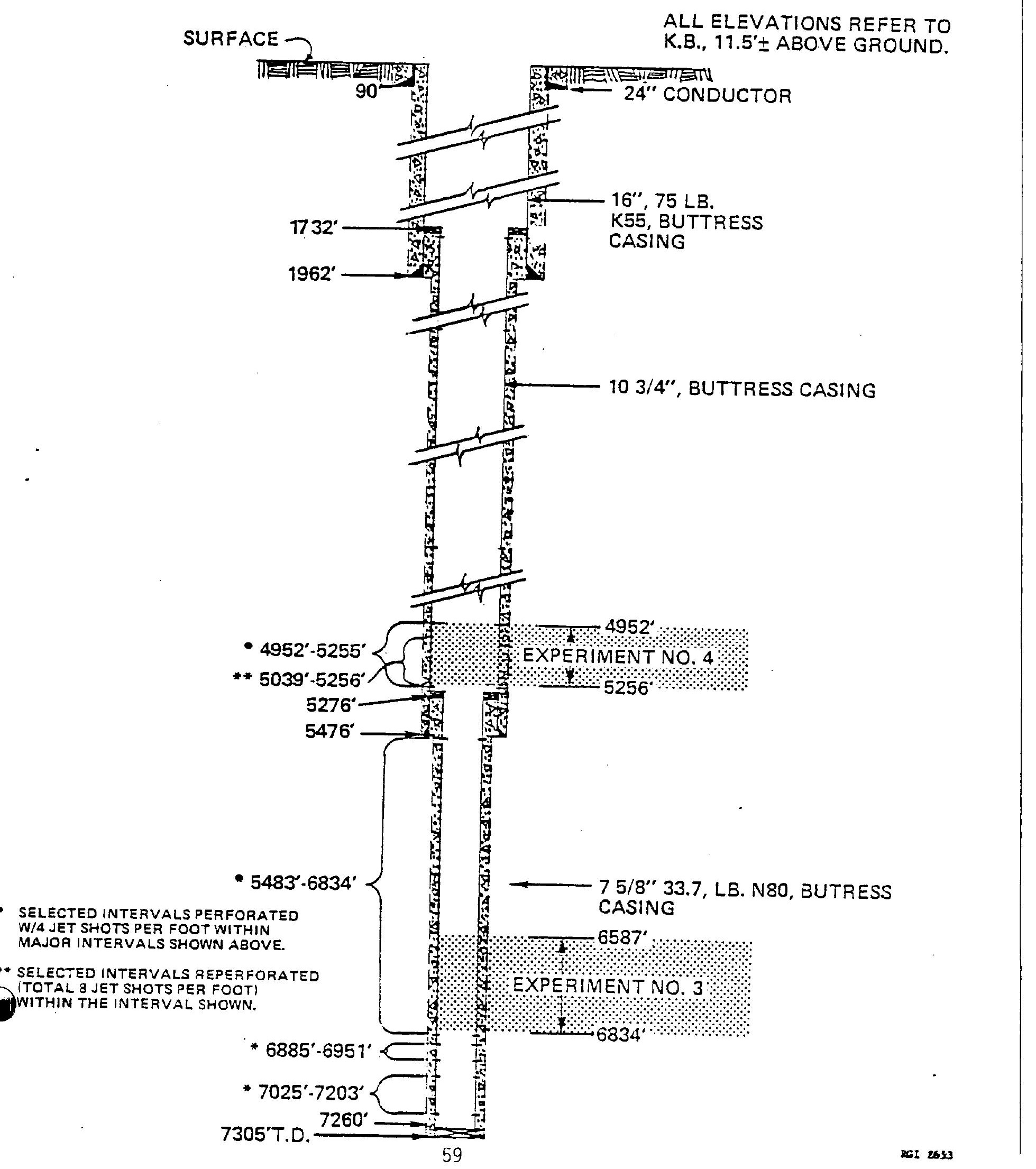


1

FIGURE 3

EAST MESA 58-30

FLOW TEST, PRIOR TO STIMULATION

(6/17-24/80)

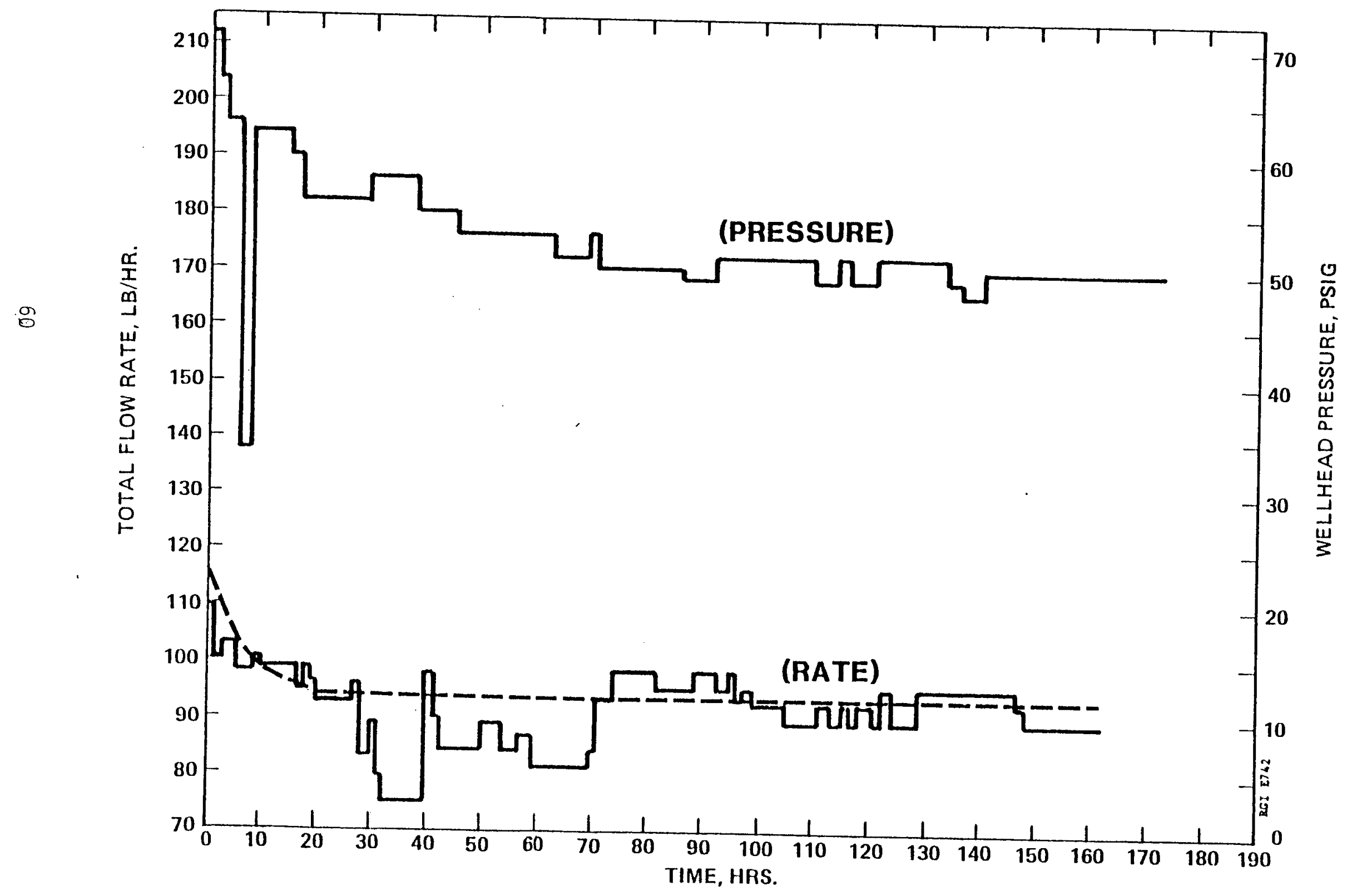


(

FIGURE 4

\section{EAST MESA 58-30}

\section{PRE-STIMULATION PRODUCTION LOG DETAILS}

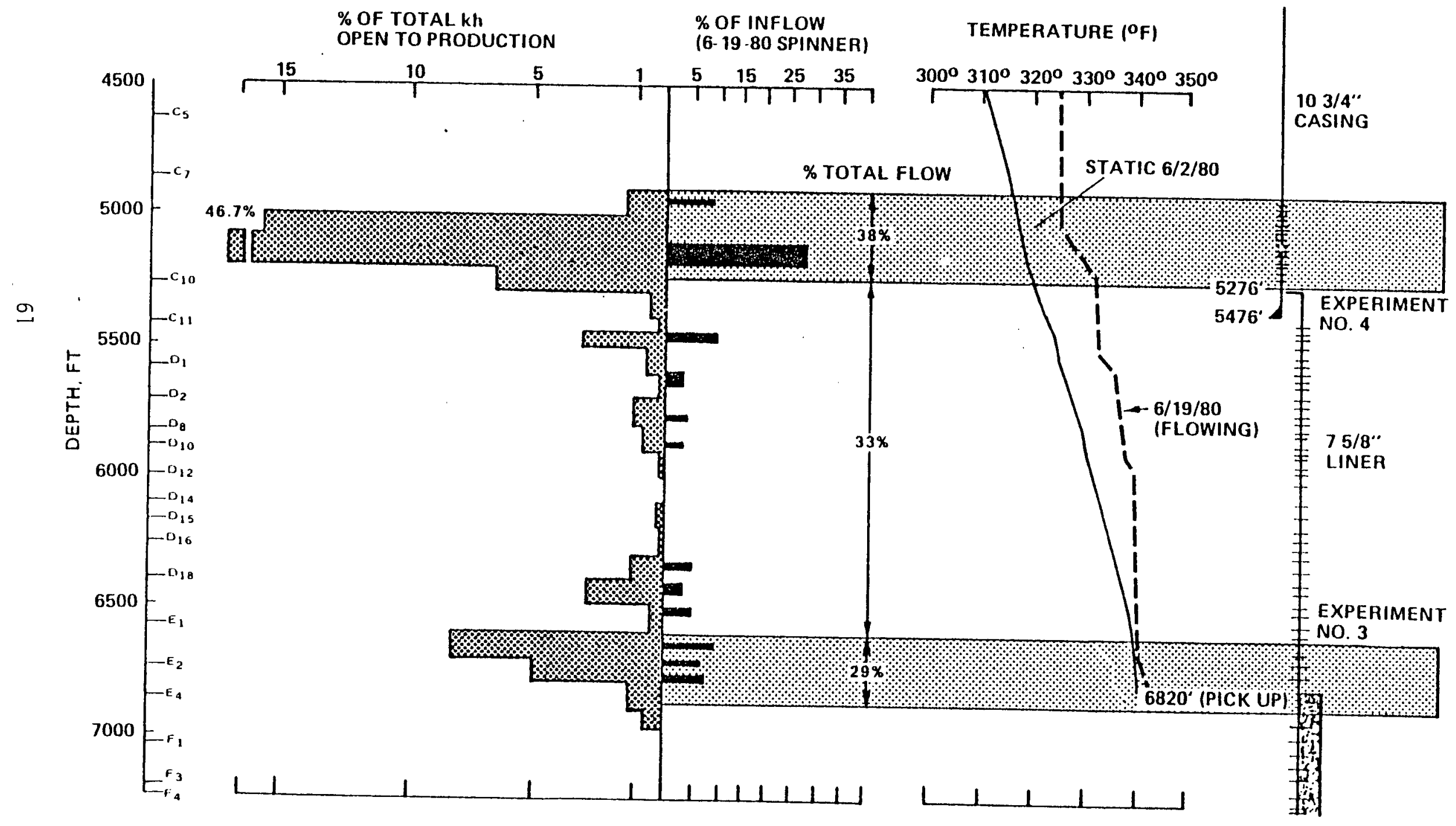


FIGURE 5

EAST MESA 58-30

HORNER BUILDUP DATA

(6/24-26/80)

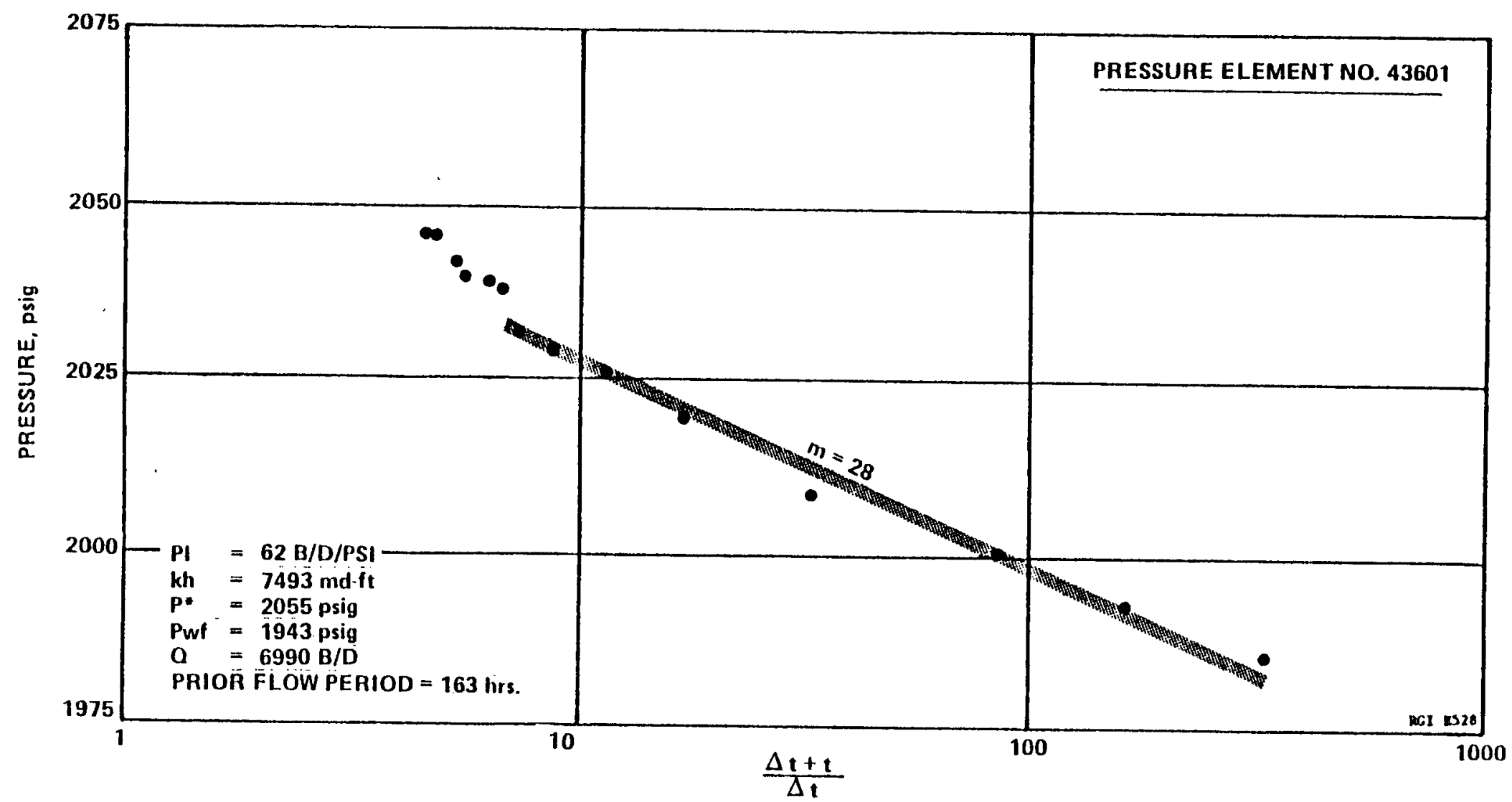



EAST MESA 58-30 EXPERIMENT NO.3

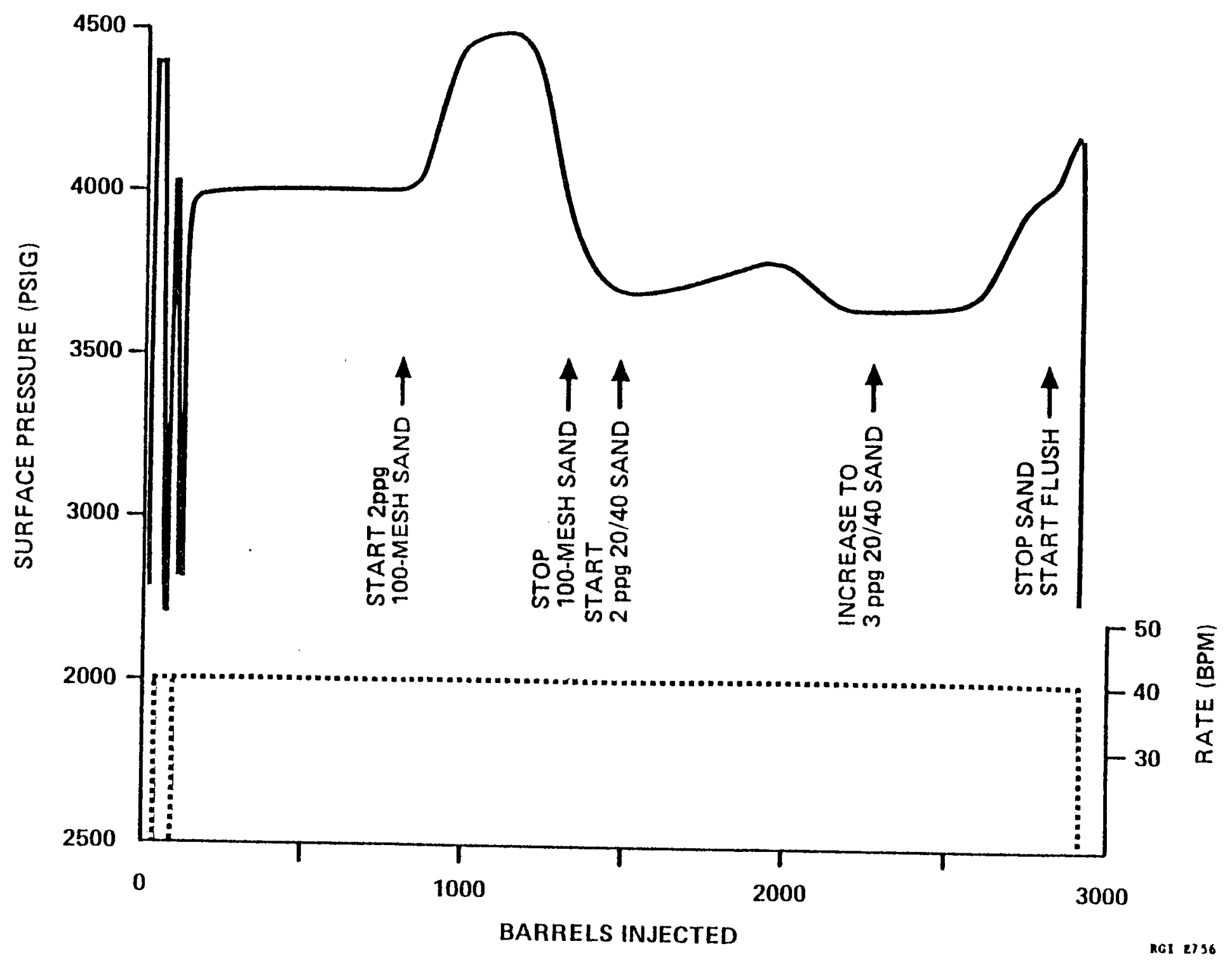




\section{FIGURE 8 \\ FLOW SCHEMATIC FOR EXPERIMENTS AT EAST MESA 58-30}

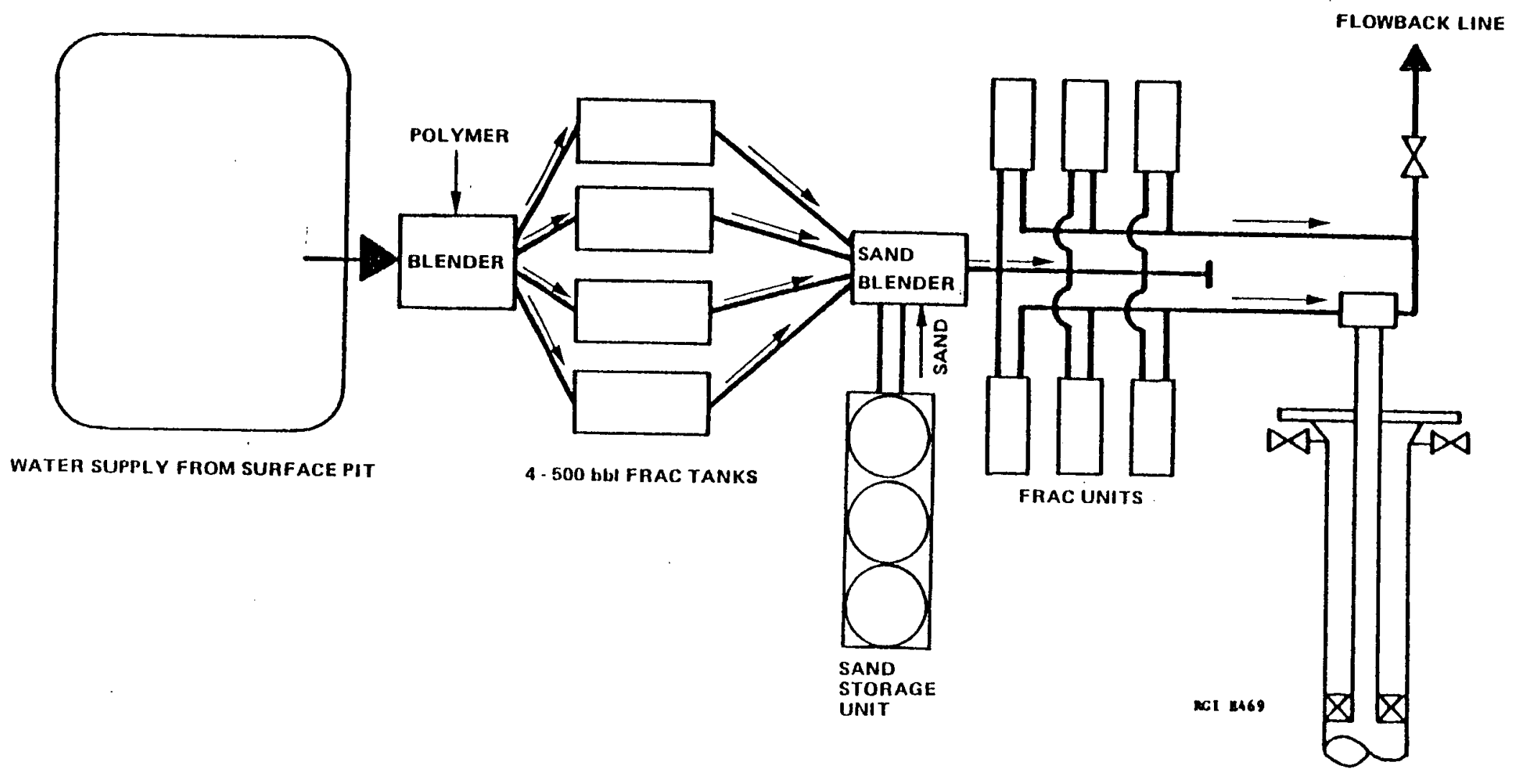


1

\section{FIGURE 9}

PRESSURE-RATE HISTORY

EAST MESA 58-30 EXPERIMENT NO. 4

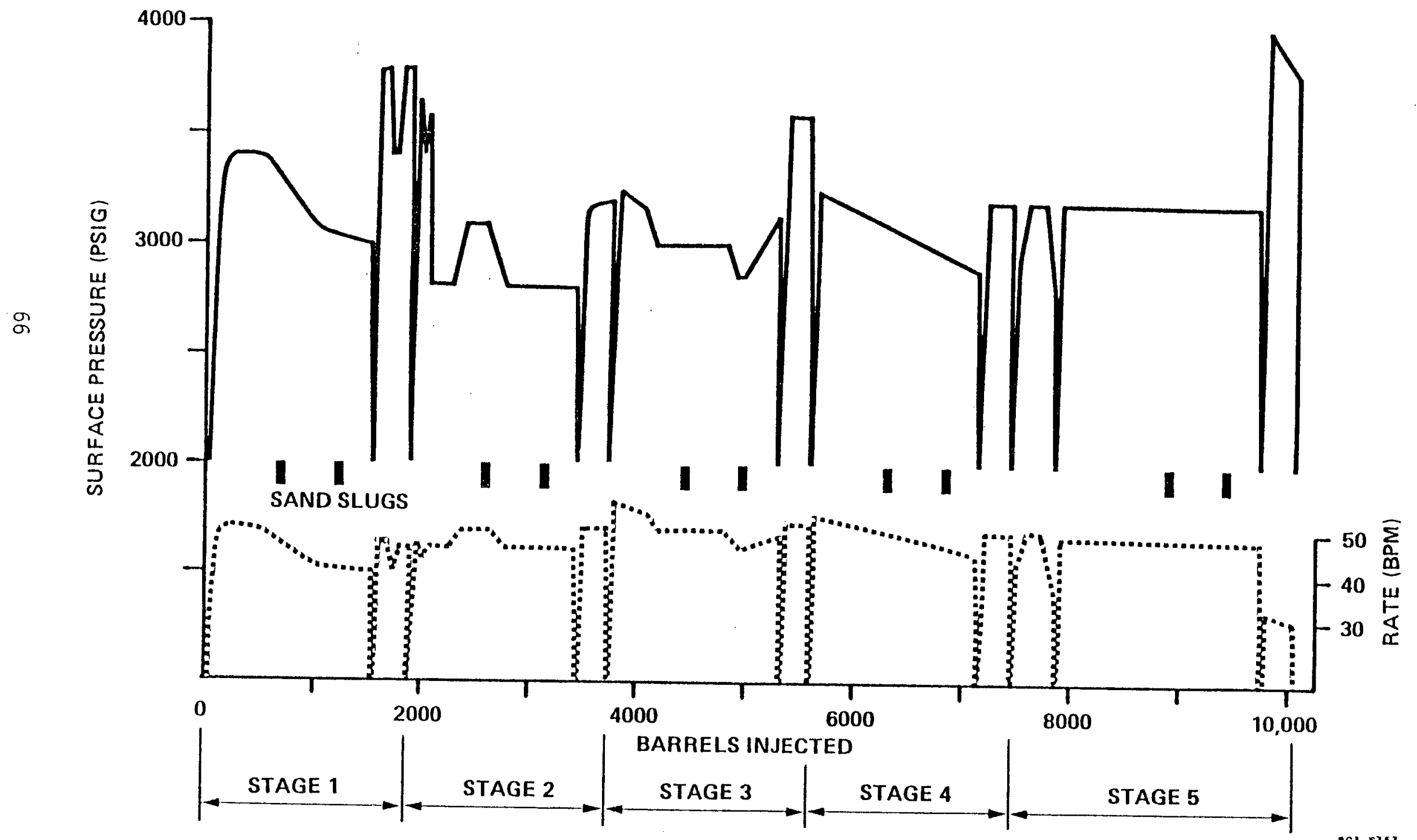


FIGURE 10

$$
\begin{gathered}
\text { EAST MESA } 58-30 \\
\text { STATIC TEMPERATURE SURVEY OF } \\
\text { UPPER AND INTERMEDIATE } \\
\text { INTERVALS AFTER EXPERIMENT NO. } 4 \\
(7-21-80)
\end{gathered}
$$

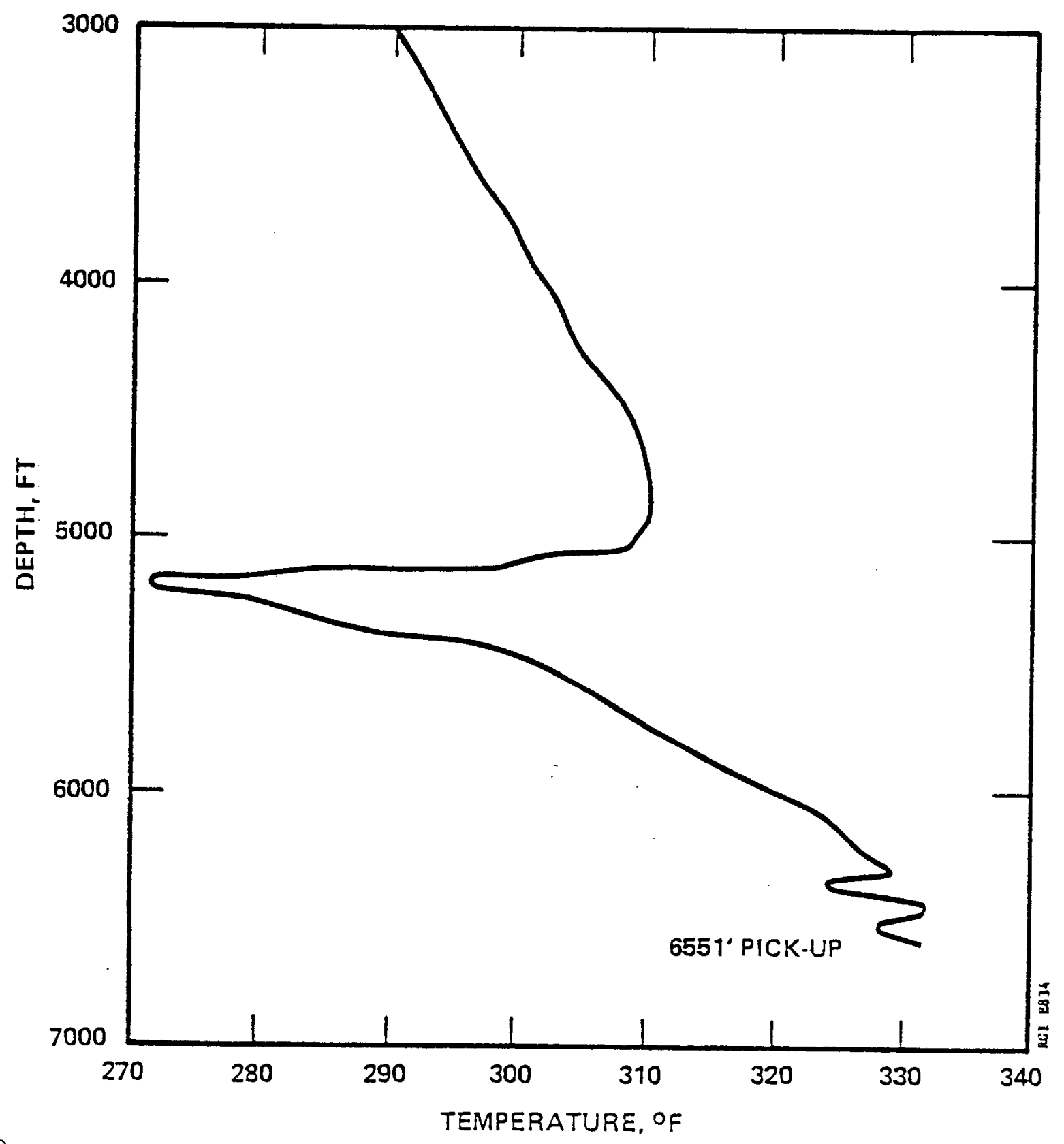


FIGURE 11

EAST MESA 58-30

FLOW TEST, UPPER AND INTERMEDIATE ZONES

$(7 / 25-8 / 2 / 80)$

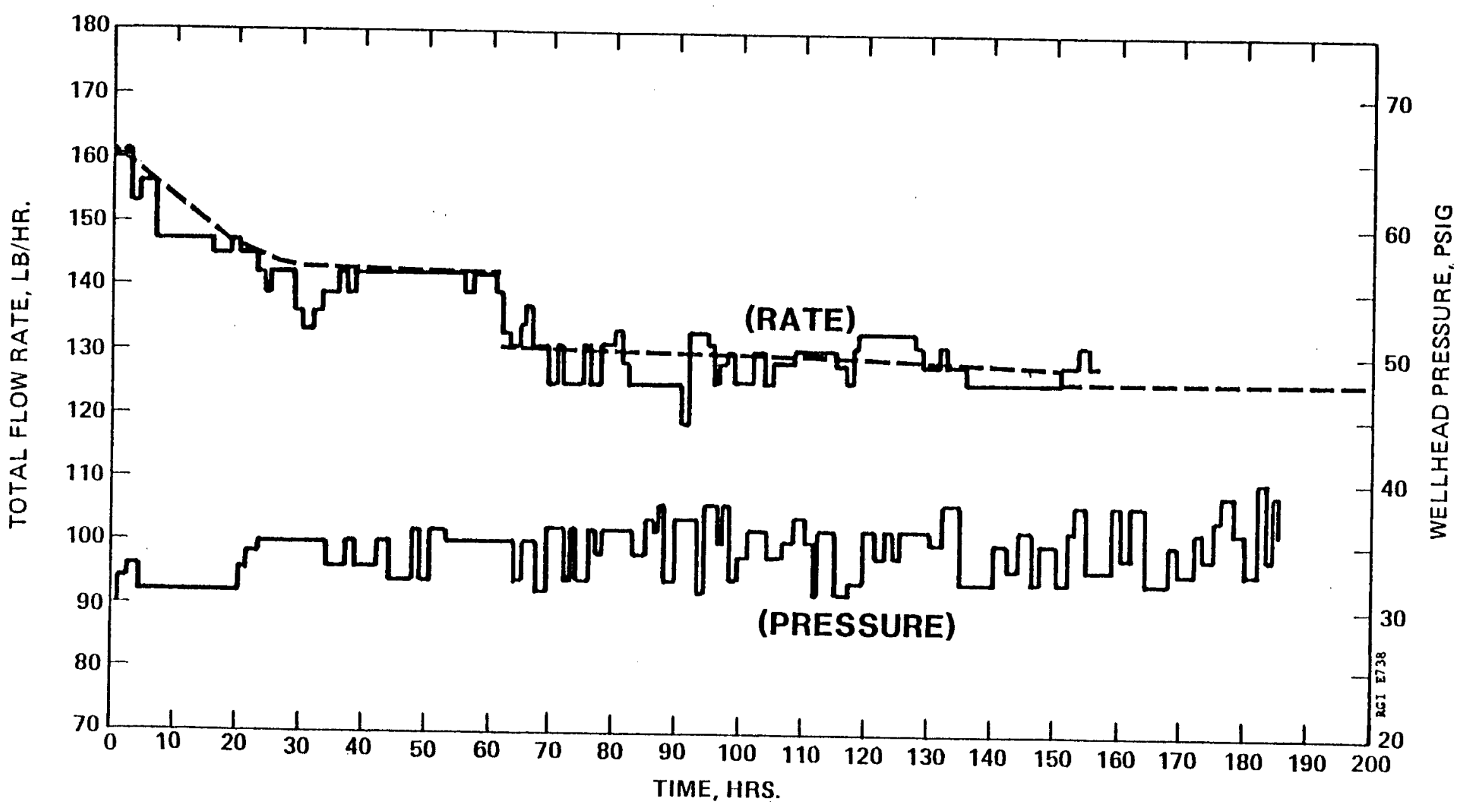


FIGURE 12

TRACER MONITORING FOR

FLOW TEST - 7/25 TO 8/2/80

(UPPER INTERVAL--EXPERIMENT NO. 4)

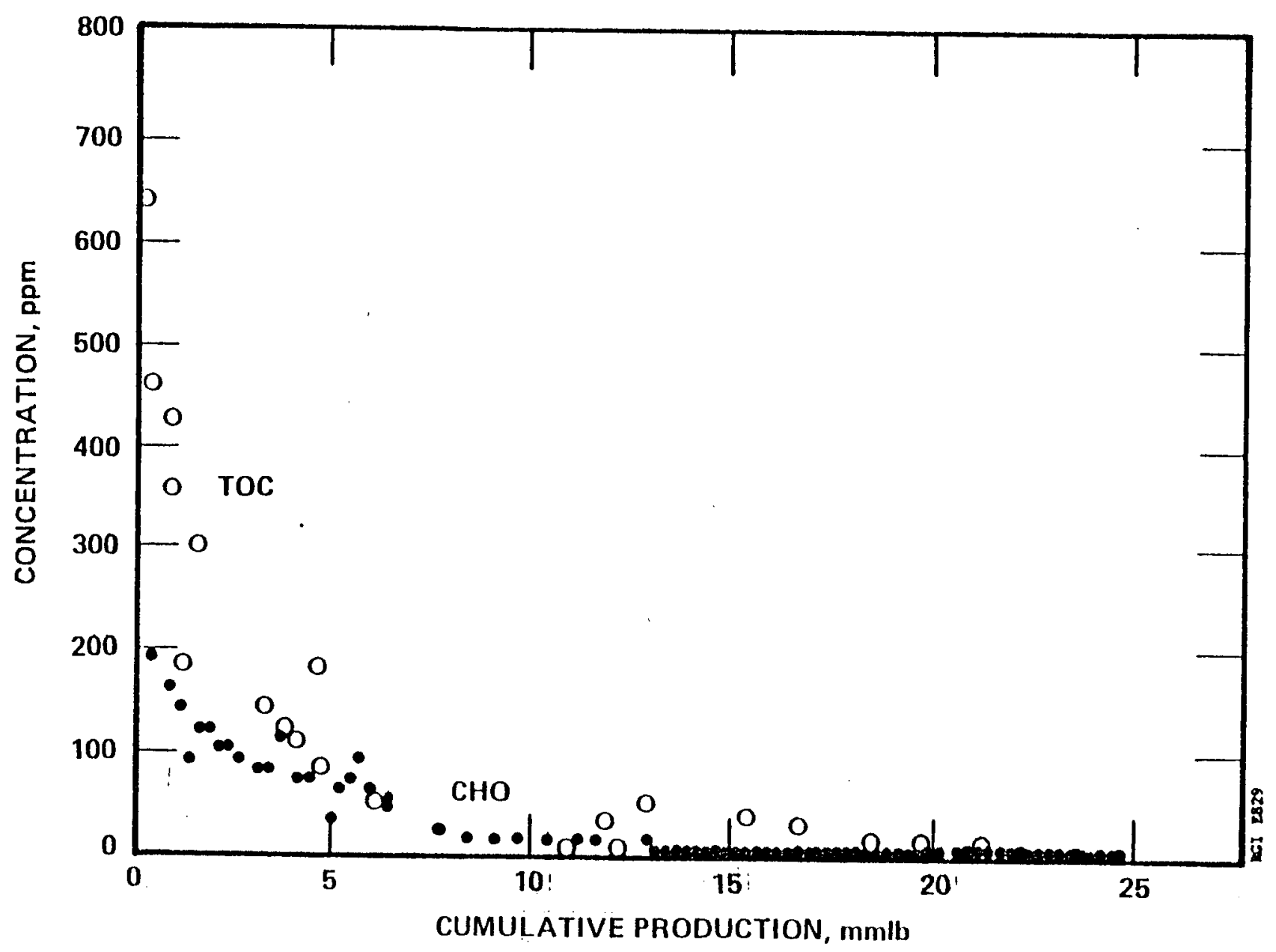




\section{TRITIUM MONITORING FOR}

FLOW TEST - 7/25/ - 8/2/80

(UPPER INTERVAL-EXPERIMENT NO.4)

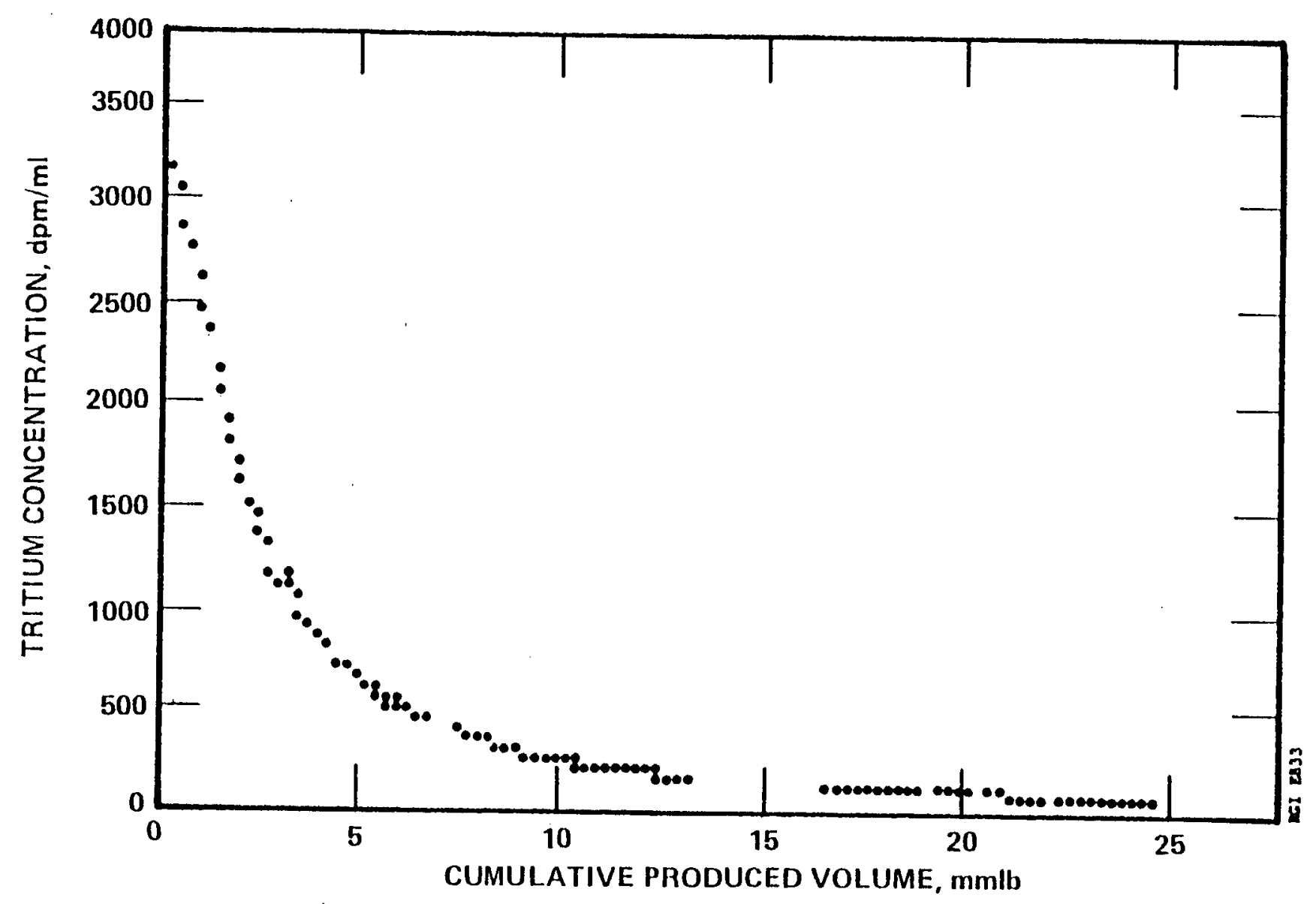


FIGURE 14

EAST MESA 58-30

LBL FLOWING TEMPERATURE SURVEY

$(7 / 30 / 80)$

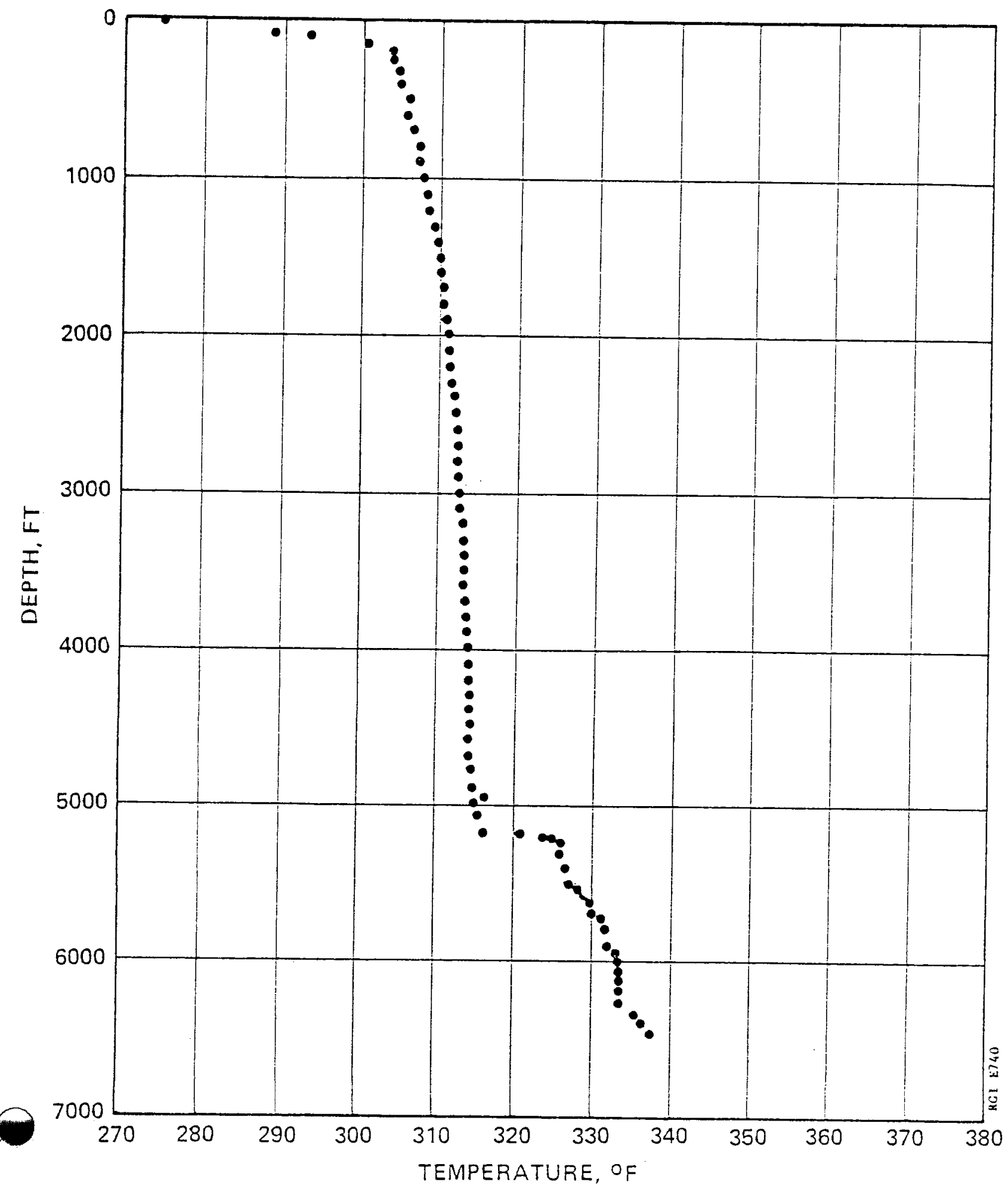


FIGURE 15

\section{EAST MESA 58-30 \\ HORNER BUILD UP DATA \\ 8/2-5/80}

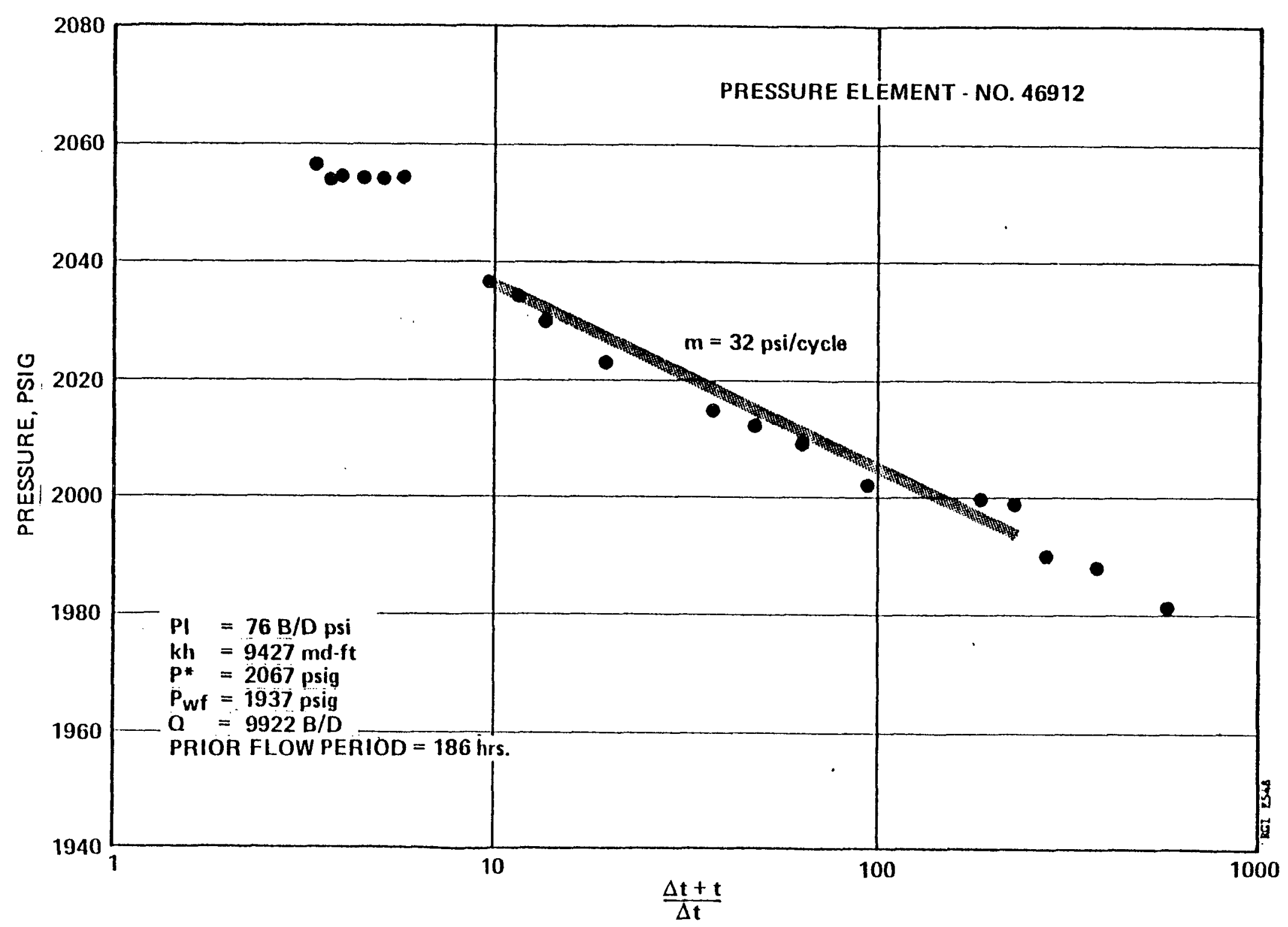


FLOW TEST, POST-STIMULATION, FULL WELLBORE OPEN 12/15-23/80

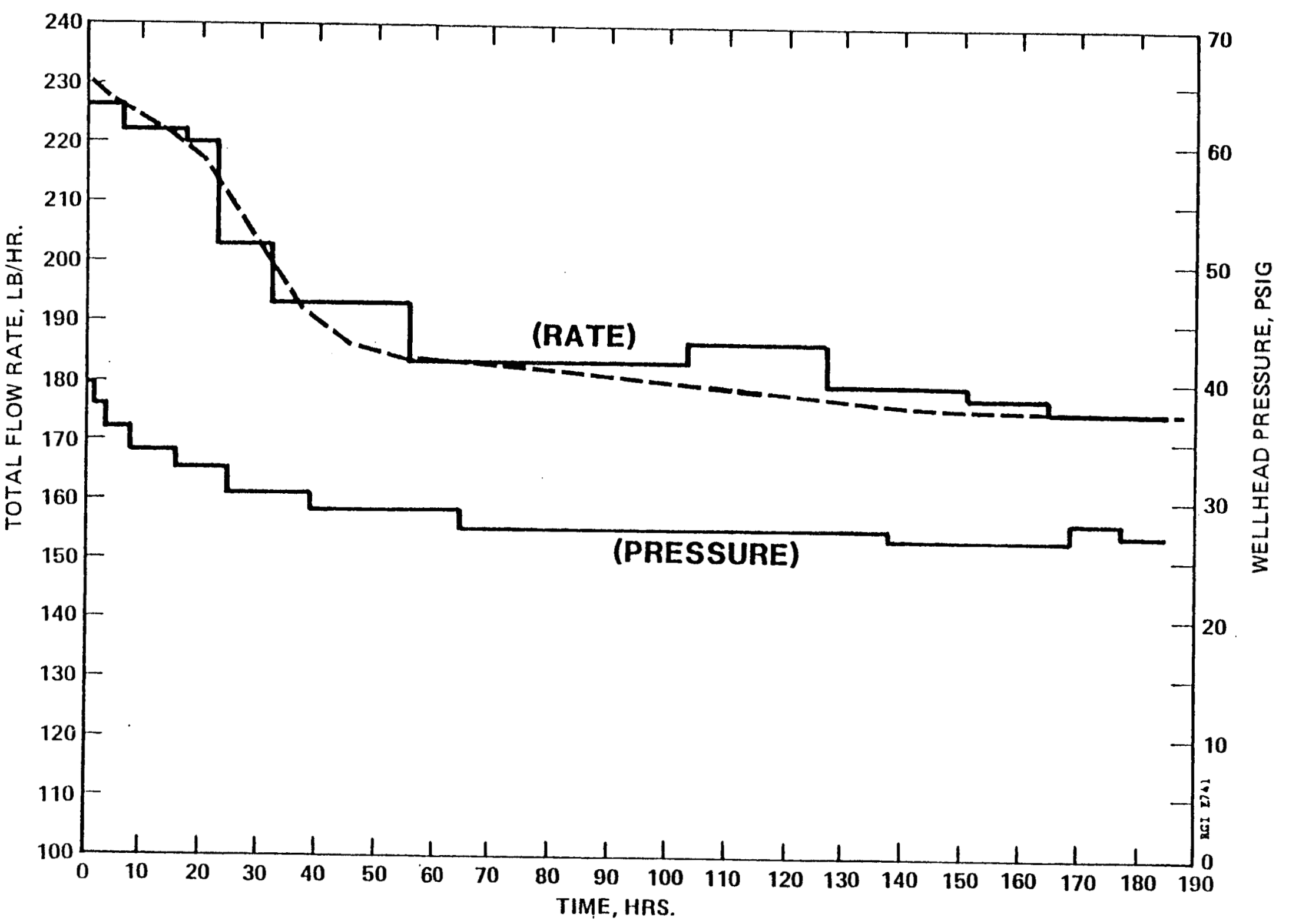




\section{FIGURE 17}

\section{EAST MESA 58-30 \\ POST-STIMULATION PRODUCTION LOG DETAILS}
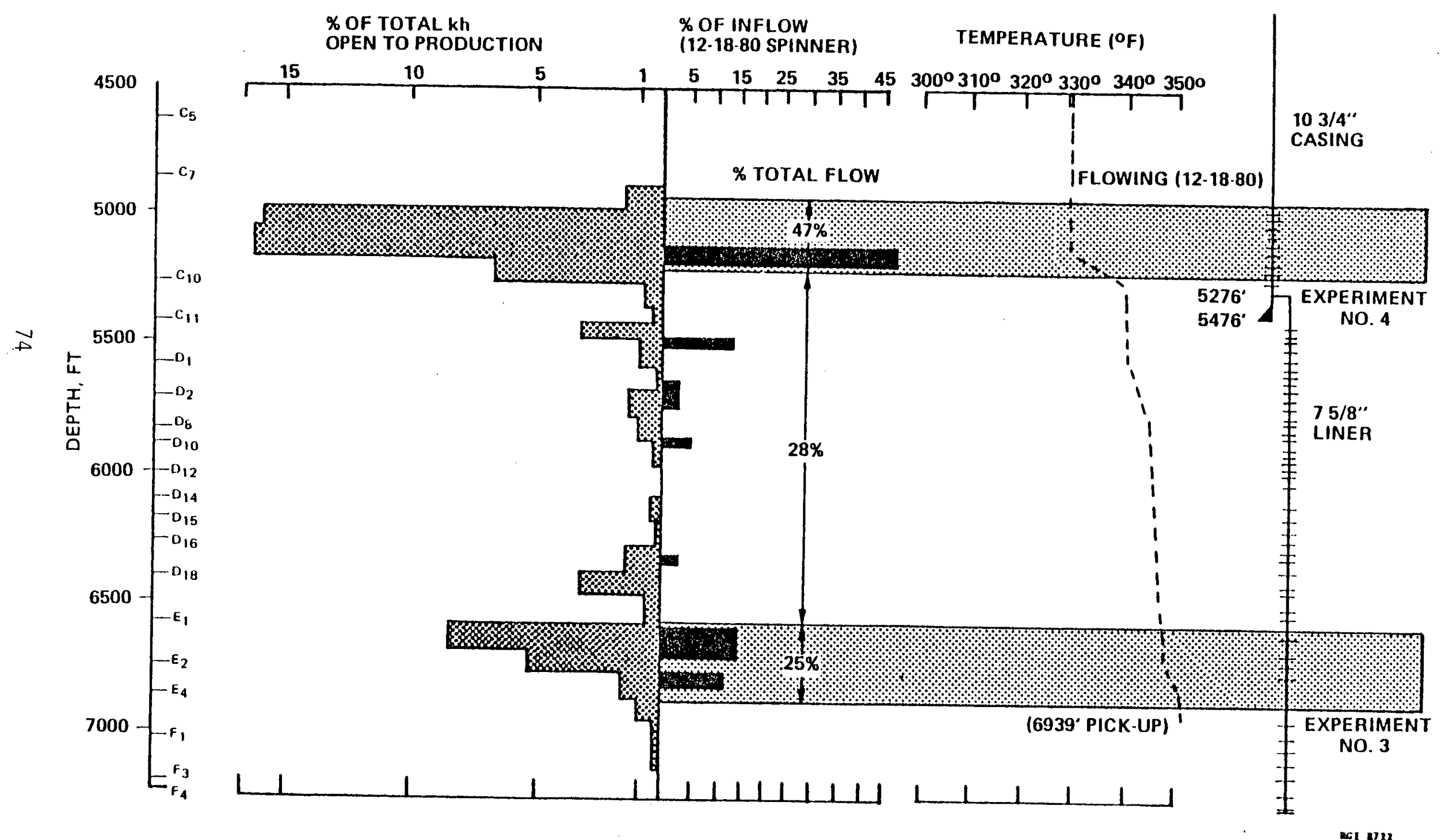
1

FIGURE 18

TRACER MONITORING FOR

SECOND FLOW TEST - 12/15-23/80

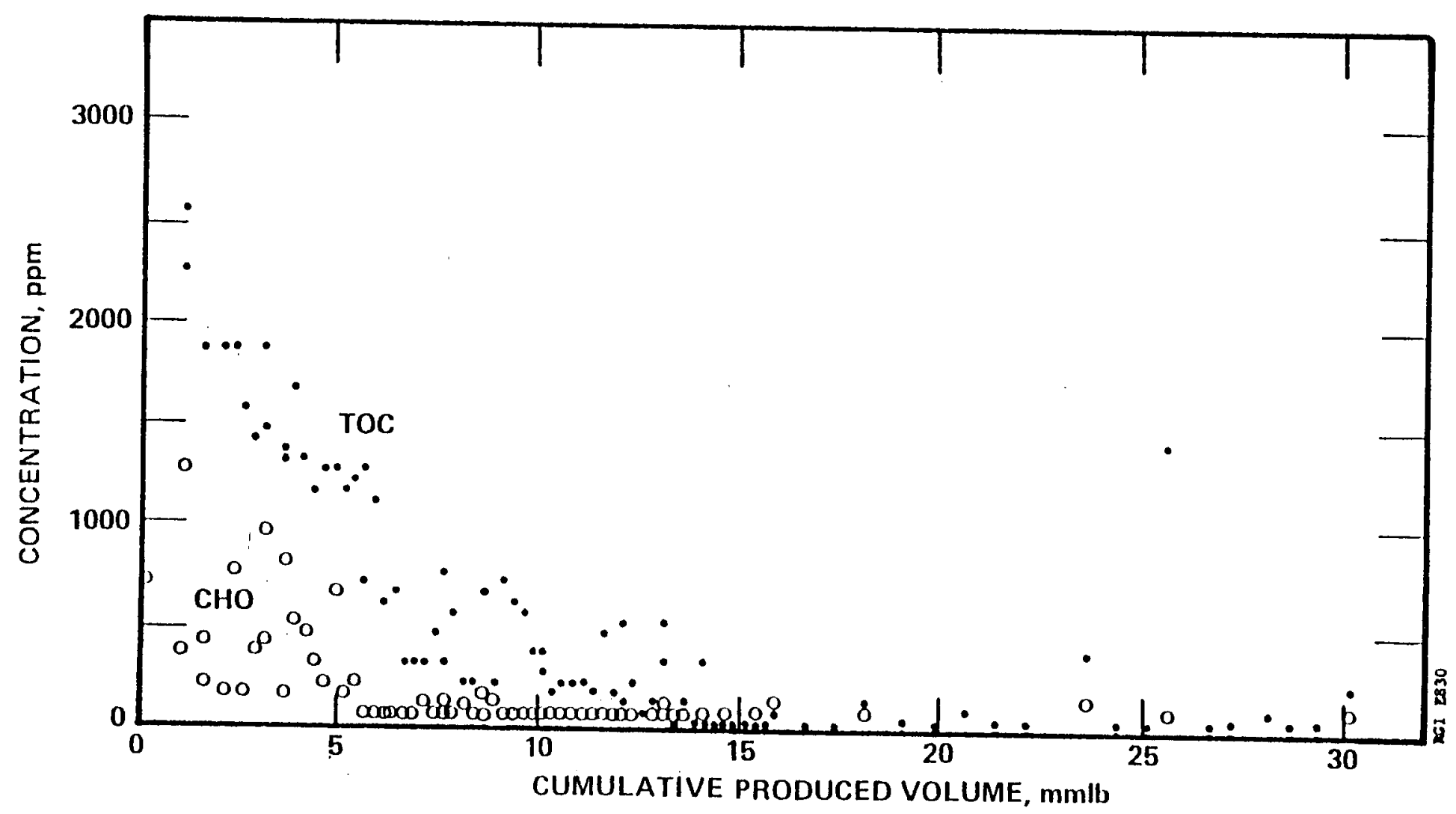


FIGURE 19

TRITIUM TRACER MONITORING FOR SECOND FLOW TEST - 12/15-23/80

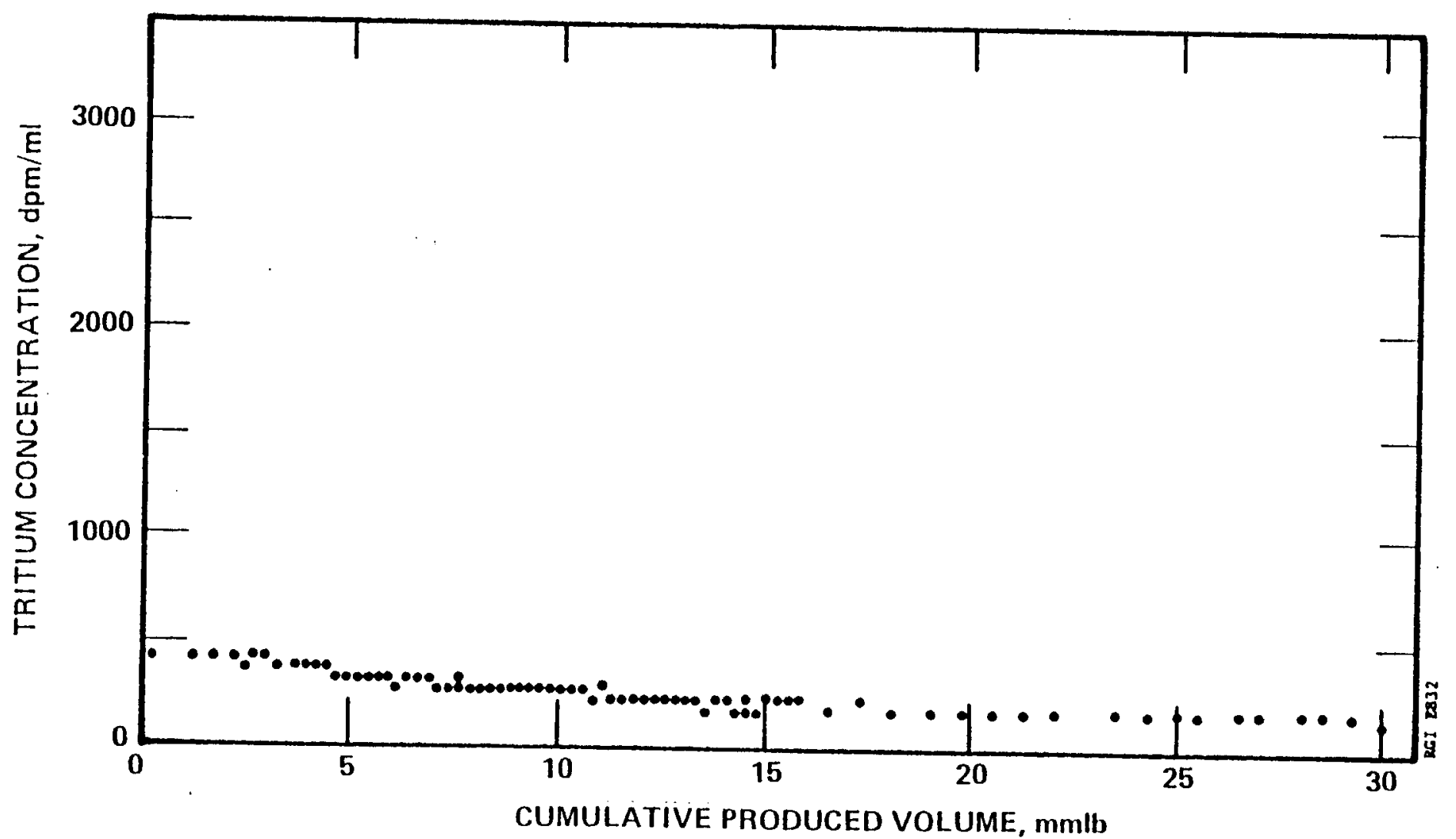




\section{APPENDIX A \\ HISTORY OF TESTING AND FRACTURE STIMULATION \\ EAST MESA 58-30}

May $12-16,1980$

Prepare for Flow Test \& Fracture Stimulation

Reconnected flow line to separators at 56-30 location. Installed control valve on south separator, moved in and set portable tanks and transfer pump. Started and ran both transfer pumps.

Modified flow line from 58-30 and added capability to flow from injector to supply water to pit at 58-30. Pipeline and facilities complete; ready for flow test.

May 17-June 1, 1980

No activities

June 2, 1980

Static Temperature Survey \& Flow Test

Triangle Services rigged up and ran static temperature survey from surface to bottom. Located top of fill at $6820^{\prime}$.

Opened well at approximately $1500 \mathrm{hrs}$ and began flowing. Flowed an estimated $8500 \mathrm{~B} / \mathrm{D}$ rate until end of day. All produced fluid (3300 BBL) put in pits at 56-30 and 52-29; sample taken for analysis.

June 3,1980

Flow Test \& Spinner Survey

Flowed well 24 hrs at estimated water rate of 7500 B/D. 4690 BBL put in pit at 52-29, remainder injected into 52-29 well.

Triangle Services rigged up and attempted to get spinner survey; however, tool malfunctioned, did not get survey. Rigged down and moved off location, will attempt to get another survey this weekend providing they can get their tools repaired.

June 4,1980

Flow Test

Flowed well 24 hrs at average rate of 7250 B/D. All produced fluid injected into 52-29.

June 5,1980

Flow Test

Flowed well 24 hrs at average rate of $7550 \mathrm{~B} / \mathrm{D}$. All produced fluid injected into 52-29. 
June 6,1980

Flow Test with Temperature \& Pressure Surveys

Flowed well at average rate of $7800 \mathrm{~B} / \mathrm{D}$ until $1745 \mathrm{hrs}$, then shut well in. RIH with company wireline tools and obtained flowing pressure and temperature surveys. POH checking charts, looked good. made up new tools. RIH to 4900'. Sat for l hr, then closed well in.

June $7-9,1980$

Waiting on spinner logging truck

June 10, 1980

Flow Test for spinner survey

Opened well and flowed from 1315 hrs until 1530 hrs and discontinued operations when word was received that spinner truck had mechanical problems and would not be able to survey well until later.

Clean out \& Enlarge Pit for Water Storage

Moved in drag line and Caterpillar and began working on pit.

June 11,1980

Clean Out and Enlarge Pit for Water Storage

Continued working on pit with drag line and bulldozer

June 12,1980

Clean Out and Enlarge Pit for Water Storage for Fracture Stimulation

Completed drag Iine work, continued shaping pit with bulldozer.

Rough grading of pit approximately 758 complete.

Flow Test for spinner survey

Began flowing at approximately 1315 hrs and flowed for remainder of day at estimated average rate of $7500 \mathrm{~B} / \mathrm{D}$. All produced fluid

injected into 52-29.

June 13,1980

Clean Out and Enlarge Pit for Fracture Stimulation Water storage

Completed shaping of pit. Will start hauling in clay for liner, Monday, June $16,1980$.

Flow Test for spinner Survey

Flowed well 16 hrs at average rate of $6800 \mathrm{~B} / \mathrm{D}$. LBL ran spinner survey to bottom and attempted temperature sirvey but couldn't get by adapter at $5276^{\prime}$. Shut well in at 1600 hrs. All produced fluid injected into 52-29.

June 14-15, 1980

No activities 
June 16,1980

Clean Out and Enlarge Pit for Fracture stimulation Water Storage

Began hauling and spreading clay liner for pit.

June 17,1980

Flow Test

Opened well at 1430 hrs and began flowing. Flowed at 6800 B/D rate until end of day, all produced fluid injected into 52-29.

Clean Out and Enlarge Pit for Fracture Stimulation Water storage

Continued hauling and spreading clay for pit liner. Clay hauling completed and liner in place.

June 18,1980

Flow Test

Flowed well 24 hrs; 18 hrs at average rate of $6600 \mathrm{~B} / \mathrm{D}$ and 6 hrs at $5400 \mathrm{~B} / \mathrm{D}$. All produced fluid injected into 52-29.

Clean Out and Enlarge Pit for Fracture Stimulation

Began hauling and spreading rock on top of clay liner.

June 19, 1980

Flow Test with Temperature \& Spinner Surveys

Flowed well 24 hrs at average water rate of $6200 \mathrm{~B} / \mathrm{D}$ with all

produced fluid injected into 52-29. Triangle services ran flowing temperature and spinner surveys.

Clean Out and Enlarge Pit for Fracture Stimulation

Completed spreading of rock, pit now complete.

June 20, 1980

Flow Test

Flowed well 24 hrs at average rate of 5900 B/D. All produced fluid injected into 52-29.

June 21,1980

Flow Test

Flowed well 24 hrs at average rate of 5900 B/D. All produced fluid injected into 52-29. 
June 22,1980

Flow Test

Flowed well $24 \mathrm{hrs}$ at average rate of $5800 \mathrm{~B} / \mathrm{D}$. All produced fluid injected into 52-29.

June 23, 1980

Flow Test \& Pressure Survey

Flowed well 24 hrs at average rate of $5800 \mathrm{~B} / \mathrm{D}$. Moved in Sandia wireline operated by LBL personnel for pressure buildup survey, but couldn't get tool to work correctly. Will run company wireline and Ruster tools tomorrow. All produced fluid injected into 52-29 except for 950 BBLS put in pit at 56-30. Sample taken for analysis.

June 24,1980

Flow Test \& Pressure Buildup Survey

Flowed well until 0930 hrs at average rate of $5800 \mathrm{~B} / \mathrm{D}$, then shut in. Prior to shut-in, RIH with company wireline and Kuster pressure instruments and sat at $4900^{\prime}$ for $1 / 2 \mathrm{hr}$.

All produced fluid (2300 BBLS) put in pit at 56-30. Sample taken for analysis.

June 25,1980

Pressure Buildup Survey

Kuster pressure instruments in hole at $4900^{\circ}$ for pressure buildup data.

June 26,1980

Remove Survey Instruments - Prepare Well for Fracture Stimulation

POH with Kuster pressure tools at $0700 \mathrm{hrs}$, checked charts, looked good. Mixed and pumped in $550 \mathrm{BBLs}$ of $9.1 \mathrm{lb} / \mathrm{gal} \mathrm{KCl}-\mathrm{NaCl}$ water and killed well. Removed tree, installed BOP, moved killing equipment from location and began moving 4-1/2" tubing on location. Ready for rig to move in.

June 27,1980

Prepare for Fracture Stimulation

MIRU Alco Well Service rig. Made up scraper and bumper sub and began picking up 4-1/2" tubing and RIH to 1900'. Shut down for night.

June 28,1980

Prepare for Fracture stimulation

Continued picking up tubing and RIH to 5000'. Shut down early to modify tubing racking fingers to equip 4-1/2" tubing. Spotted 6 frac tanks on location. 
June 29,1980

Prepare for Fracture Stimulation

Continued picking up tubing, ran scraper to $6715^{\prime}$ (K.B.) and began POH. Pulled approximately 6000', then shut down for night.

June 30,1980

Prepare for Eracture stimulation

Finished POH, made up Baker tubing tester, and mechanical collar locator. RIH to 6537', located collar, set tubing tester and attempted to test tubing. Tubing did not test, began POH.

July 1,1980

Prepare for Fracture Stimulation

Continued POH, made up Lynes packers and 10 joints of 3-1/2" tubing above top packer. Began testing in hole with Hydro-Test.

July 2,1980

Prepare for Fracture stimulation

Continued testing in hole. Packers hanging at 6567'. Stripped on Grant rotating head, hooked up frac equipment, shut down due to darkness. Pumped water in hole at $2500 \mathrm{~B} / \mathrm{D}$ rate during night to cool well and packer rubbers.

July 3,1980

Fracture Stimulation

Reconnected fracturing equipment, pumped water for 30 minutes then set packers with lower packer at $6572^{\prime}$, upper packer at $6529^{\prime}$. Pumped lower zone frac job, released packers and pulled up $20^{\prime}$ with no drag. Hung at that depth while rigging down frac 1 ines and preparing to $\mathrm{POH}$. Started to $\mathrm{POH}$ and found packers stuck. (After packers were released, frac fluid apparently flowed upward carrying frac sand which settled out on top of packers.) Worked packers up and down, finally freed up. Began POH, pulling extremely slow due to difficulty in breaking connections on 4-1/2" tubing. Broke power tongs and shut down. Ordered out new set from Long Beach.

July 4,1980

Fracture Stimulation

New tongs arrived, broke out two stands and lost belt on $r$ ig hydraulic pump. Replaced belt, checked out system, hydraulic pressure too low. Shut down rig and ordered out another separate hyaraulic unit.

July 5,1980

Fracture Stimulation

Set up separate hydraulic unit and began puliing tubing. Many connections could not be unscrewed without heating collars. ID and 
broke out Lynes packers, made up Baker bridge plug, Full Bore packer, and tubing tester and RIH to 5270' and set plug.

July 6,1980

Fracture Stimulation

Pulled packer to 4458'. Rigged up BJ-Hughes, tested frac Iines to 5000 psi and attempted to set packer, packer didn't set. Worked up and down several times, finally set. spotted 10 sx of sand then pumped 10,300 BBL Erac job at average 48 BPM and 3200 psi surface pressure. Flowed back 120 BBL, unset packer and pulled up to $4156^{\prime}$. Rigging up for temperature survey.

July 7,1980

Clean Out After Fracture stimulation

RIH with temperature survey tools but couldn't go below 4150', POH. $\mathrm{POH}$ with tubing and found bridge plug still attached to bottom of packer. Missing from bottom of bridge plug were 3 drag springs, the lower drag ring and cone, and the castellated nut. Ordered out impression block and magnet.

July 8,1980

Clean Out After Fracture Stimulation

Impression block and magnet arrived at 11:30 a.m. Made up impression block and RIH to $1732^{\prime}$ and set down on intermediate liner hanger

twice, then got through. Ran on in hole, set down and POH. Impression block showed only top liner adaptor marks. Made up magnet, RIH to 2000t, noticed bad spot in sand line, POH. Rigged up Sandia wireline and ran temperature survey to 5211 ' where tool set down. Ordered out Baker tubing bailer.

July 9,1980

Clean Out After Fracture Stimulation

RIH with Baker tubing bailer and set down on solid material at 5273'. Pulled up to 4844' where tubing started pulling wet, shut down for night.

July 10,1980

Clean Out After Fracture stimulation

Kicked pump to tubing and attempted to pump kill fluid down tubing at 1000 psi, but could not. Shut down and called for Mccullough

Services to shoot hole in tubing.

JuIy II, 1980

Clean Out After Fracture Stimulation

Set up McCullough Wireline Services, RIH to $416 I^{\prime}$ and shot perforating gun. Attempted to pump kill fluid down tubing but could not. RIH again with MCCullough perforating gun and shot at 4I5I', tubing went on a vacuum. Pumped in 30 BBLS of 9.1 Ibs KCl-NaCl water and began POH with tubing. 
July 12,1980

Shut down

July 13,1980

Clean Out After Fracture Stimulation

Finished POH with tubing bailer, recovered approximately 12 Iineal

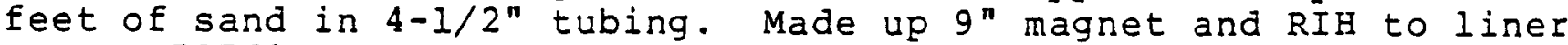
top at 5276' and POH recovering one broken drag spring and 3 pieces of cast iron broken off from lower cone. Made 2 more runs with 9 " magnet without recovery. RIH with 5" magnet without recovery. Shut down for night.

July 14,1980

Clean Out After Fracture Stimulation

Made up 3-5/8" bailer and RIH to top of junk and $P O H$ recovering small piece of cast iron lodged between flapper and seat. RIH again and stuck bailer, attempted to pull free but could not. Shut down rig and ordered out fishing tools.

July 15,1980

Clean Out After Fracture Stimulation

Picked up overshot with 7-3/4" OD skirt, bumper sub and hydraulic jars and began RIH on 4-1/2" tubing, stripping over sand line. RIH to $3076^{\prime}$ and shut down for night.

July 16,1980

Clean Out After Fracture Stimulation

Continued RIH stripping over sand line. Set down and latched on to fish at 5235'. Jarred bailer loose and pulled two stands with fish dragging. Shut down and set up cable splicer and wireline services for tomorrow morning.

July 17,1980

Clean Out After Fracture Stimulation

Spliced sand line at surface and attempted to cut cable downhole with Kinley cutter. Cutter would not work but sand line pulled out of rope socket and all sand line was recovered. POH with tubing to $2700^{\prime}$ when rig hydraulic pump failed. Shut down and repaired pump.

July 18,1980

Clean Out After Fracture Stimulation

POH and recovered fish. Made up 9 " OD magnet and RIH on sand line to liner top at 5276' and POH recovering cone shaped casting lost from bottom of bridge plug. Made another run to liner top, no recovery. Ran 5" magnet to 5717' (end of sand line) and $P O H$, no recovery. Shut down until Monday, July 21. 
July 21, 1980

Temperature Log After Fracture Stimulation

Set up Triangle Services and RIH with sinker bar to 6545' where tool set down. POH, set up temperature tool and RIH and surveyed from $2000^{\prime}$ to $6545^{\prime}$ and POH.

Spliced new sand line on rig.

July 22,1980

Clean Out After Fracture Stimulation

Made up 5" magnet and made several runs to sand fill at $6545^{\prime}$ recovering small broken cast pieces and 1 bolt out of bottom cone assembly. Made up bailer and RIH getting full load of fine sand.

RIH with 4-1/2" tubing to 1615' and shut down, will begin laying down tubing tomorrow.

July 23, 1980

Prepare to Flow Test After Fracture stimulation

LD 75 joints of $4-1 / 2^{\prime \prime}$ tubing.

JuIY 24,1980

Prepare to Flow Test After Fracture stimulation

Finished laying down 4-1/2" tubing.

JuIy 25, 1980

Flow Test After Fracture Stimulation

Made up 5" magnet and RIH to top of fill at 6547' and POH, no recovery. LDMO rig. Removed BOP, installed tree and flow line. Rigged up Nowsco coiled tubing unit and nitrogen truck. RIH with coiled tubing to $300^{\prime}$ and began injecting nitrogen at 300 scfm while lowering tubing to $405^{\prime}$. Twenty minutes after nitrogen started, well began unloading. Lowered tubing down to 500' and stopped, continued to pump nitrogen at $300 \mathrm{scfm}$. Pumped nitrogen a total of 2 hrs and 40 minutes unloading well in excess of $20,000 \mathrm{~B} / \mathrm{D}$ rate. At 1600 hrs shut off nitrogen and $P O H$, well died temporarily then began to flow on its own. Continued to flow well remainder of day at estimated rate of $10,000 \mathrm{~B} / \mathrm{D}$. All produced fluid (4585 BBLS) put into pit at 56-30.

July 26,1980

Flow Test After Fracture Stimulation

Flowed well 24 hrs at average rate of $9000 \mathrm{~B} / \mathrm{D}$. All produced fluid (9000 BBLS) put into pits at 56-30 and 52-29. 
July 27,1980

Flow Test After Fracture Stimulation

Flowed well $24 \mathrm{hrs}$ at average rate of $8800 \mathrm{~B} / \mathrm{D}$. All produced fluid (8800 BBLS) put into pits at 56-30 and 52-29.

July 28,1980

Flow Test After Fracture Stimulation

Flowed well 24 hrs at average rate of $8700 \mathrm{~B} / \mathrm{D}$. 5517 BBLS injected into well 52-29, remainder (3263 BBLS) put into pits at 56-30 and 52-29.

July 29,1980

Flow Test After Fracture Stimulation

Flowed well $24 \mathrm{hrs}$ at average rate of $8600 \mathrm{~B} / \mathrm{D}$. All produced fluid injected into 52-29. Rigged up LBL and attempted to take flowing downhole fluid samples, without results.

July 30,1980

Flow Test After Fracture stimulation

Flowed well $24 \mathrm{hrs}$ at average rate of $8250 \mathrm{~B} / \mathrm{D}$. All produced fluid injected into 52-29. LBL ran flowing temperature survey and obtained fluid sample at $6300^{\prime}$.

July 31, 1980

Flow Test After Fracture Stimulation

Flowed well $24 \mathrm{hrs}$ at average rate of $8250 \mathrm{~B} / \mathrm{D}$. All produced fluid injected into 52-29.

LBL attempted Spinner survey but slug flow of well made it impossible to accurately measure flow.

August 1, 1980

Flow Test After Fracture Stimulation

Flowed well 24 hrs at average rate of $8300 \mathrm{~B} / \mathrm{D}$. All produced fluid injected into 52-29.

LBL attempted to get flowing pressure survey but tools did not work correctly. RDMO LBL.

August 2, 1980

Flow Test After Fracture Stimulation

Flowed well until 1150 hrs at average rate of $8300 \mathrm{~B} / \mathrm{D}$, then shut well in. Prior to shut-in, RIE with company wireline and instruments and hung for approximately $1-1 / 2$ hrs at 4900 '.

All produced fluid reinjected except for 1000 BBLS saved in surface tanks to be used for lower zone clean out. 
August $3-5,1980$

No Activities

August 6, 1980

Clean Out Well with Coiled Tubing

Opened well at 0730 hrs and began flowing at approximately 0745 hrs. NowsCo coiled tubing unit and nitrogen truck arrived and began rigging up. Shortly afterward, Haliburton pump truck arrived and rigged up. At 0935 hrs began RIH with coiled tubing. With tubing at $160^{\prime}$ began pumping nitrogen $1200 \mathrm{scfm}$ and water at 1 BPM, continued lowering tubing until it stopped at the 16" hanger at 1732'. (Coiled tubing depth meter showed 1719'.) Attempted several times to get by hanger without results. $\mathrm{POH}$, put an "S" bend in the tubing and RIH again and entered hanger without problems and stopped at $1800^{\prime}$. Resumed pumping nitrogen and water, waited $20 \mathrm{mins,}$ then began lowering tubing. Entered second hanger at 5276' without hitting it. Continued on in hole to 6178' where tubing stopped, pulled back to $6100^{\prime}$ then continued on in hole to 6370' where tubing pressure dropped. Pulled tubing back to 5198', checked nitrogen and water pumpers to make sure they were both pumping - o.k. Resumed POH and at 5162' tubing $\mathrm{POH}$ open-ended. Left approximately 5170' tubing in hole.

Approximately 4800 BBLS put in pits at 56-30 and 52-29.

August 7,1980

Prepare to Fish Coiled Tubing

Moved 4" tubing from location and began moving kill fluid mixing equipment on location and hooking up.

August 8 - November 26, 1980

Fish Coiled Tubing

Fished coiled tubing and cleaned out well to top of sand fill at $6516^{\prime}$.

November $27,28, \& 29,1980$

Shut Down. Combination $3-1 / 2^{n}$ and 2-7/8" tubing work string hanging at $6506^{\prime}$ with BOP shut in.

November 30,1980

Clean Out Sand Fill

Pumped in 141 BBL of produced fluid to displace tubing.

December 1, 1980

Clean Out Sand Fill

Opened well and began flowing through tubing. Cleaned out fill from $6516^{\prime}-6600^{\prime}$. 
December 2, 1980

Clean Out Sand Fill

Cleaned out fill from 6600'-6692'. Had difficulty in zones 6610'-6615'; 6650'-6661'; and from 6670'-6675'. Circulated out a lot of formation sand, some frac sand, and pieces of packer rubber.

December 3, 1980

Clean Out Sand Fill

Replaced packing on power swivel. Cleaned out from 6692'-6721' where tubing plugged up. Worked tubing and finally got it flowing again at greatiy reduced rate. Rate gradually increasing as sand flowed out, flowed a tremendous amount of sand and lost hole back to 6707'.

December 4,1980

Clean Out Sand Fill

Co from 6707'-6716' then plugged tubing. Pumped in $\mathrm{KCl}$ - NaCl water and killed tubing. Removed large pieces of packer rubber from all 4 tubing safety valves and started $\mathrm{POH}$.

December 5, 1980

Clean Out Sand Fill

Finished POH, made up 6-1/2" bit and RIH to 6693', tagged fill, pulled up 12' and displaced tubing with $141 \mathrm{BBL}$ of produced fluid.

December 6,1980

Clean Out Sand Fill

CO sand from 6693'-6804'.

December 7, 1980

Shut down

December 8,1980

Clean Out Sand Fill

Co sand, both frac and formation from 6804'-6900'.

December 9, 1980

Clean Out Sand Fill

CO sand from 6900'-6979' and let well flow for 5 hrs through tubing

in order to clean up.

December 10, 1980

Lay Down Tubing

Checked for fill, no fill; pulled and LD all tubing. 
December 11, 1980

Lay Down Move Out

LD 4 joints 5-3/4" WP. RIH to 60' with electric submersible pump. Lifted out approximately 150 BBL kill fluid, then shut well in. Removed BOP; LDMO rig.

December $12,13 \& 14,1980$

No activities

December 15,1980

Flow Test

Began flow test. Installed flow tree, connected up flow line and started flowing at $1515 \mathrm{hrs}$. Initial water flow rate $17,500 \mathrm{~B} / \mathrm{D}$. Final rate $15,000 \mathrm{~B} / \mathrm{D}$. Flowed an estimated $6015 \mathrm{BBL}$ into pit at 56-30.

December 16,1980

Flow Test

Flowed well $24 \mathrm{hrs}$ at declining rate. Initial water rate 15,000 $B / D$. Final rate $14,000 \mathrm{~B} / \mathrm{D}$. Flowed an estimated $8820 \mathrm{BBL}$ into pits at 56-30 and 52-29 prior to starting injection into 52-29.

December 17, 1980

Flow Test

Flowed well 24 hrs at declining rate. Initial water rate 14,000 $\mathrm{B} / \mathrm{D}$. Final rate $13,000 \mathrm{~B} / \mathrm{D}$. All produced fluid injected into 52-29.

December 19, 1980

Flow Test and Spinner Survey

Flowed well for 24 hrs at semi-stable rate. Initial water flow rate $12,700 \mathrm{~B} / \mathrm{D}$. Final rate $12,700 \mathrm{~B} / \mathrm{D}$. All produced fluid injected into $52-29$.

Spinner survey was run on well.

December 20,1980

Flow Test

Flowed well $24 \mathrm{hrs}$. Initial rate $12,700 \mathrm{~B} / \mathrm{D}$. Final rate 12,192

$B / D$. All produced fluid injected in 52-29.

December 21,1980

Flow Test

Flowed well for $24 \mathrm{hrs}$. Initial flow $12,192 \mathrm{~B} / \mathrm{D}$. Final rate 11,952 $B / D$. All produced fluid injected into $52-29$. 
December 22,1980

Flow Test

Flowed well $24 \mathrm{hrs.} \mathrm{Initial} \mathrm{flow} \mathrm{rate} 11,952 \mathrm{~B} / \mathrm{D}$, final rate 11,601 B/D. All produced fluid injected into 52-29.

December 23,1980

Flow Test and Pressure Survey

Flowed well 10 hrs and 45 minutes. Initial rate $11,601 \mathrm{~B} / \mathrm{D}$, final rate $11,424 \mathrm{~B} / \mathrm{D}$. All produced fluid injected into 52-29. Prior to shut-in, RIH with pressure instruments to monitor pressure buildup. Well shut in at 10:45 a.m.

December $24-28,1980$

Pressure Builaup Survey

Pressure instruments in hole.

December 29,1980

Buildup Survey

pulled pressure instruments from well. Charts looked good.

December 30,1980 - January 6, 1981

No activities

January 7,1981

Fill survey

RIH with sinker bar and found sand fill at 6919'. Stimulation and testing complete. 